\title{
The Quantification of Acceleration Events in Elite Team Sport: a Systematic Review
}

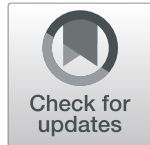

Robert I. M. Delves ${ }^{1}$, Robert J. Aughey ${ }^{1 *} \mathbb{D}$, Kevin Ball ${ }^{1}$ and Grant M. Duthie ${ }^{2}$

\begin{abstract}
Background: Wearable tracking devices are commonly utilised to quantify the external acceleration load of team sport athletes during training and competition. The ability to accelerate is an important attribute for athletes in many team sports. However, there are many different acceleration metrics that exist in team sport research. This review aimed to provide researchers and practitioners with a clear reporting framework on acceleration variables by outlining the different metrics and calculation processes that have been adopted to quantify acceleration loads in team sport research.

Methods: A systematic review of three electronic databases (CINAHL, MEDLINE, SPORTDiscus), was performed to identify peer-reviewed studies that published external acceleration load in elite team sports during training and/or competition. Articles published between January 2010 and April 2020 were identified using Boolean search phrases in relation to team sports (population), acceleration/deceleration (comparators), and competition and/or training (outcome). The included studies were required to present external acceleration and/or deceleration load (of any magnitude) from able-bodied athletes (mean age $\geq 18$ years) via wearable technologies.

Results: A total of 124 research articles qualified for inclusion. In total, 113/124 studies utilised GPS/GNSS technology to outline the external acceleration load of athletes. Count-based metrics of acceleration were predominant of all metrics in this review (72\%). There was a lack of information surrounding the calculation process of acceleration with $13 \%$ of studies specifying the filter used in the processing of athlete data, whilst $32 \%$ outlined the minimum effort duration (MED). Markers of GPS/GNSS data quality, including horizontal dilution of precision (HDOP) and the average number of satellites connected, were outlined in $24 \%$ and $27 \%$ of studies respectively.

Conclusions: Team sport research has predominantly quantified external acceleration load in training and competition with count-based metrics. Despite the influence of data filtering processes and MEDs upon acceleration, this information is largely omitted from team sport research. Future research that outlines acceleration load should present filtering processes, MEDs, HDOP, and the number of connected satellites. For GPS/GNSS systems, satellite planning tools should document evidence of available satellites for data collection to analyse tracking device performance. The development of a consistent acceleration filtering method should be established to promote consistency in the research of external athlete acceleration loads.
\end{abstract}

Keywords: Acceleration, Data filtering, Activity profile, Deceleration, Wearable technology, Athlete tracking, Microtechnology, Athlete loads

\footnotetext{
* Correspondence: Robert.Aughey@vu.edu.au

${ }^{1}$ Institute for Health \& Sport, Victoria University, Melbourne, VIC 3011,

Australia

Full list of author information is available at the end of the article
}

Springer Open (c) The Author(s). 2021 Open Access This article is licensed under a Creative Commons Attribution 4.0 International License, which permits use, sharing, adaptation, distribution and reproduction in any medium or format, as long as you give appropriate credit to the original author(s) and the source, provide a link to the Creative Commons licence, and indicate if changes were made. The images or other third party material in this article are included in the article's Creative Commons licence, unless indicated otherwise in a credit line to the material. If material is not included in the article's Creative Commons licence and your intended use is not permitted by statutory regulation or exceeds the permitted use, you will need to obtain permission directly from the copyright holder. To view a copy of this licence, visit http://creativecommons.org/licenses/by/4.0/. 


\section{Key Points}

- Acceleration in team sport research has largely been quantified via the use of count-based metrics.

- There is a lack of information surrounding the processing of acceleration data in team sport research. Very few studies in this review quantified the filtering processes used to calculate acceleration and the minimum effort duration for these events. For satellite-based tracking systems, inconsistency seen in GPS/GNSS device reporting on horizontal dilution of precision and satellite number information has hindered the ability to objectively evaluate athlete acceleration and deceleration datasets.

- Future research should attempt to develop a common acceleration filtering/processing method to allow for appropriate comparison in load between studies and between tracking manufacturers. A common process would help to alleviate concerns of technology-driven variations in athlete acceleration data.

\section{Background}

Through the continued development of athlete wearable technology, team sport practitioners have increasingly elected to monitor their athlete's external load during training and competition with player-tracking devices [1]. Technologies, such as the Global Positioning System (GPS) and optical-based systems, are established playertracking methods, whilst progressions have been made in the development of local positioning systems (LPS) and access to the Global Navigation Satellite System (GNSS). Regardless of the technology implemented, the aforementioned tracking systems allow for the relatively unobtrusive and objective collection of a player's locomotion during training and match-play, with information obtained on athlete distances and speeds [1,2]. Tracking information allows for the creation of activity profiles for respective sports, which details the different load placed upon athletes and positions played within that sport $[1,3]$. For performance staff, an activity profile enables specific prescription of athlete training programs and rehabilitation processes that are centred towards preparing the athlete for the rigours of competition load [1].

The ability to change speed and direction through acceleration and deceleration are important attributes for successful performance in many team sports [4-7]. Subsequently, team sport research has produced a wide variety of metrics to assess acceleration in training and competition $[7,8]$. Given the stochastic nature of team sport movement, the assessment of acceleration is imperative in depicting the overall loads of competition [7]. For example, team sport athletes across the football codes of rugby league, rugby union, association (soccer) and Australian football represent average match speeds that would be considered low intensity at approximately 80 to $140 \mathrm{~m} \mathrm{~min}^{-1}\left(1.3-2.3 \mathrm{~m} \mathrm{~s}^{-1}\right)$ [7]. However, the aforementioned sports can see peak intensities up to 170 to $210 \mathrm{~m} \mathrm{~min}^{-1}$ during a 1 -min moving average epoch and have been shown to further increase to intensities up to $380 \mathrm{~m} \mathrm{~min}^{-1}$ with smaller moving average window lengths (e.g., $5 \mathrm{~s}$ ) [6, 9-12]. The wide range in intensities from match averages to competition peaks indicates that the ability to change velocity (acceleration) is important to performance. In invasion/combat sports such as rugby league, where general play is contested in tight confines, acceleration load is highest compared to other football codes, indicating the ability to rapidly change velocity is important to successful performance in this code $[6,9-$ 11]. Similarly, in American football, where players are also actively trying to gain or negate yardage, skill players such as wide receivers, defensive backs and linebackers accumulate substantial counts of high accelerations $\left(>3.5 \mathrm{~m} \mathrm{~s}^{-2}\right.$ ) per game (range 26-38 counts per game) [13].

Whilst being able to perform accelerations is important to successful athletic performance, quantifying accelerations is also important to practitioners for athlete load management [8]. Accelerations incorporate a significant portion of the total overall external load during team sport training and competition [8, 14-17]. However, the magnitude of acceleration efforts can provide different sources of load experienced by the athlete. For example, accelerations (positive velocity) will place a greater metabolic cost on the body compared to deceleration events, as accelerations require greater energy to fuel the change in velocity $[4,14,15,18]$. Deceleration events however differ from accelerations with respect to the mechanically demanding, eccentric loads placed upon the body when braking (particularly at higher intensities). Athlete braking (decelerating) is dampened by soft-tissue structures which attempt to attenuate the force of each deceleration effort $[8,14-17,19]$. In team sport athletes, an increased count of high-intensity accelerations is associated with neuromuscular fatigue and muscle damage (marked by increased creatine kinase) post competition $[7,8,14,20]$. Therefore, it is important that acceleration and deceleration can be appropriately quantified and monitored during training and competition to ensure athletes are adequately prepared for this $\operatorname{load}[7,9]$.

For team sport practitioners and researchers however, the existing research on acceleration and how acceleration load in competition and training is quantified, has varied greatly between studies $[7,8]$. Currently, there are a multitude of different methods in which to quantify accelerations in team sport research [21]. Specifically, acceleration in applied team sports has been quantified via 
threshold based counts, time or distance spent in certain thresholds (e.g., $>3.5 \mathrm{~m} \mathrm{~s}^{-2}$ threshold for "high-intensity accelerations") or more recently, by combining all absolute acceleration data (regardless of intensity) and averaging over a defined time period [1, 7, 20-23].

Regardless of the metric chosen to quantify acceleration, the measurement of acceleration is subject to the device quality and filtering settings of the tracking system. In GPS technology, there have been continual improvements in device capabilities, with $10-\mathrm{Hz}$ devices being deemed most valid and reliable for measuring acceleration [3, 7, 22, 24]. Varley et al. [22] determined that $10-\mathrm{Hz}$ devices could, at worst, detect an acceleration had occurred, but otherwise possessed acceptable validity for accelerations at various starting velocities in straight running (CV 3.6-5.9\%). However, deceleration at a starting velocity between 5 and $8 \mathrm{~m} \mathrm{~s}^{-1}$ had greater variability (CV 11.3\%) which was attributed to the rapid change in speed during deceleration compared to acceleration $[7,22,24]$.

To analyse the quality of positional data in GPS/GNSS devices, the horizontal dilution of precision (HDOP) and the average number of connected satellites are extracted $[1,25]$. For GPS/GNSS devices, HDOP and the number of satellites provide an indication of the quality of device connection and signal strength $[2,25]$. However, despite the importance of HDOP and the number of satellite information, the reporting of these metrics has been inconsistent in team sport research [1]. With the development of online GNSS planning tools providing evidence of the number of available satellites for a given period, researchers and practitioners should endeavour to compare the satellite tracking information from their devices to website-based tools outlining satellite availability. Extracting satellite quality information can then aid in assessing the overall data quality of metrics surrounding acceleration events. Given the importance of device signal quality on athlete positioning data, the HDOP and the number of connected satellites are significant variables that need to be reported upon in athlete-tracking research. In practice, the publishing of HDOP and satellite data then aids practitioners to determine what data they should include and exclude in their athlete load monitoring systems, including acceleration metrics. For example, HDOP values greater than one or satellite numbers less than 10 may be grounds for data exclusion in daily monitoring processes.

The processing or calculation of an acceleration event may also influence the measurement of athlete acceleration [1]. It is believed that despite the similarities in device hardware between manufacturers, the filtering and minimum effort durations in the calculation of acceleration/deceleration largely differ between devices, potentially creating technology-driven differences in acceleration/deceleration-based research [1, 26, 27]. Despite the previously stated need for greater consistency in the reporting of wearable device specifications and processes, there are still large inconsistencies in reporting of acceleration in team sport research.

With the ongoing development of athlete-tracking systems as a measure of external athlete output and the approval to implement these devices during competition, there is an increasing prevalence of the technology in team sport research $[1,8]$. Additionally, with the extensive number of studies that have outlined activity profiles of respective sports during training and competition, numerous systematic reviews have been published $[8,28-30]$. However, there is currently no systematic review that has outlined the different metrics and the calculation of the metrics used to quantify accelerations in team sport research. The systematic review from Harper et al. [8] outlined and compared high and very high-intensity accelerations in competitive team sports but this study was dependent upon cut-off thresholds, which limited the overall scope of the study. The introduction of metrics such as absolute acceleration prompted this review to include all acceleration events/ metrics regardless of the magnitude, as ultimately all acceleration and deceleration events carry a physiological cost [7]. With the inevitable further developments in player-tracking technologies (e.g., optical systems) and the importance of accelerations in team sport activity profiles, it is pertinent to review and appraise the metrics that have been used to quantify acceleration/deceleration. Therefore, the primary aim of this systematic review is to outline and compare the different methods that have been adopted to quantify acceleration and deceleration events in team sport research. A secondary aim was to identify the processing methods used by researchers in calculating acceleration/deceleration by way of data filtering methods and minimum effort durations.

\section{Methods \\ Study Design}

The current systematic review was undertaken in accordance with the Preferred items for Systematic Reviews and Meta-Analyses (PRISMA) statement on the transparent reporting of systematic reviews [31].

\section{Search Strategy}

Three electronic databases (CINAHL, Medline, and SPORTDiscus) were systematically reviewed in May 2020 by the lead author to identify articles that investigated the quantification of acceleration and/or deceleration as a metric in the load monitoring of team sport athletes in either training or competitive environments. Peer-reviewed research articles published in the English language between January 1, 2010, and April 2020 were 
reviewed for selection into the study. The search terms devised for this review were constructed using the PICO framework, where population (team sport/team sport athletes), interest (quantification of Acceleration/Deceleration metrics) and context (in competition or training) were accounted for. Search terms and exclusion criteria (Table 1) relating to team sport athletes and the quantification of acceleration and deceleration in competition or training were then identified (Table 2). Boolean operators "OR" and "AND" were used in the final search to combine all search terms together (Table 2).

\section{Screening Strategy and Study Selection}

Upon execution of the search, all returned studies were collated and exported into a reference manager (EndNote X9, Thomson Reuters, Philadelphia, PA, USA) for further review. The initial review process incorporated three stages to identify qualifying articles. Firstly, all duplicate articles were identified and removed from the reference manager. Secondly, studies were scanned via their abstracts and keywords to establish relevance. If studies were deemed to be irrelevant at this juncture, they were excluded. If doubt remained after inspection of the abstract as to the relevance of the study, it would advance to the next stage for further scrutiny. The final stage consisted of reviewing the full-text documents of each study and excluding articles that were subject to the exclusion criteria (Table 1). If doubt remained as to the eligibility of respective studies following this process, the authors resolved the process through deliberation. If an article was identified through this process or identified in any other way other than the initial search it would be subject to the same review process to determine qualification.

\section{Data Extraction}

All relevant search data were extracted into a custommade Microsoft Excel spreadsheet by the lead author. The extracted data from each eligible study included athlete population (sport, competition, age, height, weight), athlete-tracking system used (e.g., GPS, LPS or camera-based) and the associated properties (e.g., unit sample rate, HDOP, number of satellites), acceleration metrics measured (e.g., counts, distance, or average acceleration), the filtering/processing method used to quantify the acceleration and any relevant acceleration findings. All acceleration events, regardless of the magnitude were included into the analysis. There were no exclusion criteria based on the velocity threshold of the acceleration event. Similarly, all organised team activities (training and competition) were eligible for inclusion into the study. Studies that only presented information on athlete-tracking device reliability or validity in an experimental setting were excluded from analysis. Additionally, given the recent guidance on the reporting of GPS/GNSS device properties in research and similar systematic review publications, all available GPS/GNSS device information was extracted from each relevant study $[1,8]$. Specifically, the characteristics observed included HDOP, number of satellites connected during activity, device sample rate, device model and device manufacturer.

Table 1 Search inclusion and exclusion criteria

\begin{tabular}{|c|c|}
\hline \multicolumn{2}{|l|}{ Study inclusion/exclusion criteria } \\
\hline Inclusion criteria & Exclusion criteria \\
\hline Original research articles & $\begin{array}{l}\text { Systematic Reviews, Reviews, letters to the editors, non-peer reviewed } \\
\text { articles, editorial, books, periodicals, surveys, opinion pieces, conference } \\
\text { abstracts }\end{array}$ \\
\hline Team-based sports & $\begin{array}{l}\text { Outdoor court games (tennis, volleyball) water-based, ice-based and } \\
\text { sand-based sports. }\end{array}$ \\
\hline Participants with a mean age $\geq 18$ years & Research with the mean age of athletes below the age of $\leq 18$ years. \\
\hline $\begin{array}{l}\text { Elite-level, able-bodied, participants playing at the elite domestic competi- } \\
\text { tion for their respective team sport or international representation above } \\
\text { U/18 competition }\end{array}$ & $\begin{array}{l}\text { Sub-elite-level, amateur and novice athletes or athletes not playing } \\
\text { within the top tier of their respective domestic league/competitions. } \\
\text { Athletes with a physical or mental disability. Referees \& Officials }\end{array}$ \\
\hline $\begin{array}{l}\text { Official team activities: including competition/game/match observations } \\
\text { and training sessions (e.g., small sided games, match simulations, } \\
\text { individual training drills) }\end{array}$ & $\begin{array}{l}\text { Validation or reliability studies on wearable technologies using athletes } \\
\text { in an experimental setting }\end{array}$ \\
\hline $\begin{array}{l}\text { GPS/GNSS-based trackers (sampling } \geq 5 \mathrm{~Hz} \text { ) } \\
\text { Optical/LPS-based Camera Systems }\end{array}$ & Accelerometers \\
\hline $\begin{array}{l}\text { Acceleration or deceleration events measured during designated team } \\
\text { activities of any magnitude and measured in any available metric (e.g., } \\
\text { counts, metres, time spent, average acceleration, acceleration load) that is } \\
\text { not combined with any separate metric (e.g., metabolic power) }\end{array}$ & $\begin{array}{l}\text { Combined metrics (metabolic power, repeat high-intensity efforts, } \\
\text { PlayerLoad) }\end{array}$ \\
\hline Research available in English (full text) & $\begin{array}{l}\text { Research articles that are not published in English or cannot be } \\
\text { accessed in English. }\end{array}$ \\
\hline
\end{tabular}


Table 2 Search terms and keywords used in each database. Searches 1, 2, 3 and 4 were combined with "AND"

\begin{tabular}{|c|c|}
\hline Key search terms & Related search terms \\
\hline $\begin{array}{l}\text { 1. Acceleration/ } \\
\text { Deceleration }\end{array}$ & accelerat* OR decelerat* OR metabolic power OR metabolic load OR energetic cost \\
\hline $\begin{array}{l}\text { 2. Athlete tracking } \\
\text { System }\end{array}$ & $\begin{array}{l}\text { global positioning system* OR GPS OR global navigation satellite system* OR GNSS OR local positioning system* OR LPS OR } \\
\text { microtechnology OR microsensor* OR tracking system* OR athlete tracking system OR notational analysis OR camera-based } \\
\text { tracking OR optical tracking system }\end{array}$ \\
\hline 3.Team sport & $\begin{array}{l}\text { team sport* OR team-sport* OR intermittent sport OR professional team sport OR elite sport OR elite team sport OR austra- } \\
\text { lian rules football OR australian rules OR australian football OR australian football league OR AFL OR australian football team } \\
\text { OR australian rules football team OR australian football club OR australian rules football club OR soccer OR soccer player OR } \\
\text { soccer team OR football OR footballer OR football player OR football team OR field hockey OR field hockey athlete OR field } \\
\text { hockey player OR rugby league OR rugby OR rugby league player OR rugby league team OR rugby football OR rugby league } \\
\text { competition OR rugby union OR rugby union player OR rugby union competition OR rugby union club OR rugby sevens OR } \\
\text { rugby sevens competition OR lacrosse OR lacrosse competition OR american football OR american football player OR na- } \\
\text { tional collegiate athletic association OR NCAA OR gaelic football OR gaelic football player OR hurling OR hurling player OR } \\
\text { cricket OR netball OR basketball }\end{array}$ \\
\hline 4.Training/competition & $\begin{array}{l}\text { movement demands OR movement pattern OR external load OR external demands OR physical workload OR physical } \\
\text { demand* OR activity demand* OR activity profile OR activit* profile* OR match profile OR match demand* OR match play } \\
\text { OR match-play OR match intensit* OR game load* OR game intensit* OR competit* demand* OR training OR training de- } \\
\text { mands OR practice OR small sided games OR match simulation OR game simulation }\end{array}$ \\
\hline
\end{tabular}

\section{Results}

\section{Search Results}

The combined search of three databases returned 706 studies $($ SPORTSDiscus $=263$, Medline $=272$, CINAHL = 171) for analysis. All 706 studies were exported into a reference manager where 357 articles were removed as being duplicates. This resulted in the screening of 349 titles and abstracts. Of these titles and abstracts, 167 articles were deemed well outside the scope of the review and were subsequently removed. In total, 182 full-text articles were reviewed and assessed relative to the parameters of the inclusive criteria. Upon review of all fulltext articles, 62 were excluded based on athlete skill level $(\mathrm{n}=27)$, athlete age $(\mathrm{n}=14)$, GPS device sample rate ( $\mathrm{n}$ $=12)$, inappropriate study type $(\mathrm{n}=3)$ and other exclusions (including accelerometer derived acceleration and the use of combined metrics such as metabolic power) $(\mathrm{n}=6)$. A total of 120 studies remained at the completion of this process. Additionally, four studies were identified and included outside of the database search via the review process for this research. Therefore, 124 studies were included. Figure 1 identifies the classification of studies and pathway of eligibility into the study.

\section{Study Characteristics}

The accepted studies in this review outlined acceleration load during an organised, elite team sport activity. This was measured through various player-tracking technologies, including GPS/GNSS, local positioning systems or optical-based tracking systems. The results of this review are focused on how acceleration was quantified in these studies and the metrics used to present the external acceleration load. The characteristics of each of the included studies are summarised in Table 3.

\section{Team Sport Characteristics}

The team sport characteristics of each of the 124 studies are featured in Table 4 . Of the 124 articles, research from Soccer provided the greatest contribution of studies to the review (33.9\%), followed by Rugby League (14.2\%), Australian Football (11.8\%) and Field Hockey (11.0\%). Athlete sex was mixed in each sport contribution, with the exception of Australian and American Football, Basketball, Hurling, Rugby League, Rugby League Nines and Ultimate Frisbee.

\section{Tracking Device Characteristics}

The wearable technology type, as well as respective manufacturers and devices, are outlined in Table 5. Global Positioning System/GNSS-based studies were assessed on two data quality metrics. HDOP (mean \pm SD) and the number of satellites (mean $\pm \mathrm{SD}$ ) in connection with the GPS device during athlete tracking were observed in this review. Of the 113 eligible GPS/GNSS studies, $23.9 \%$ (27/113 studies) of the included articles specified the mean HDOP for their research. For the number of satellite connections during the tracking period, 27.4\% $(31 / 113)$ of studies specified the mean \pm SD value. This information is presented in Table 6 .

\section{Acceleration Processing Characteristics}

The processing methods studies implemented to calculate acceleration events are outlined in Table 7. The velocity/acceleration filters that were implemented to process athlete movement data was specified by $12.9 \%$ (16/124 studies) of the studies included in this review. The minimum effort duration for the calculation of acceleration metrics were specified in $32.3 \%$ (40/124 studies) of the included studies. The specified minimum 


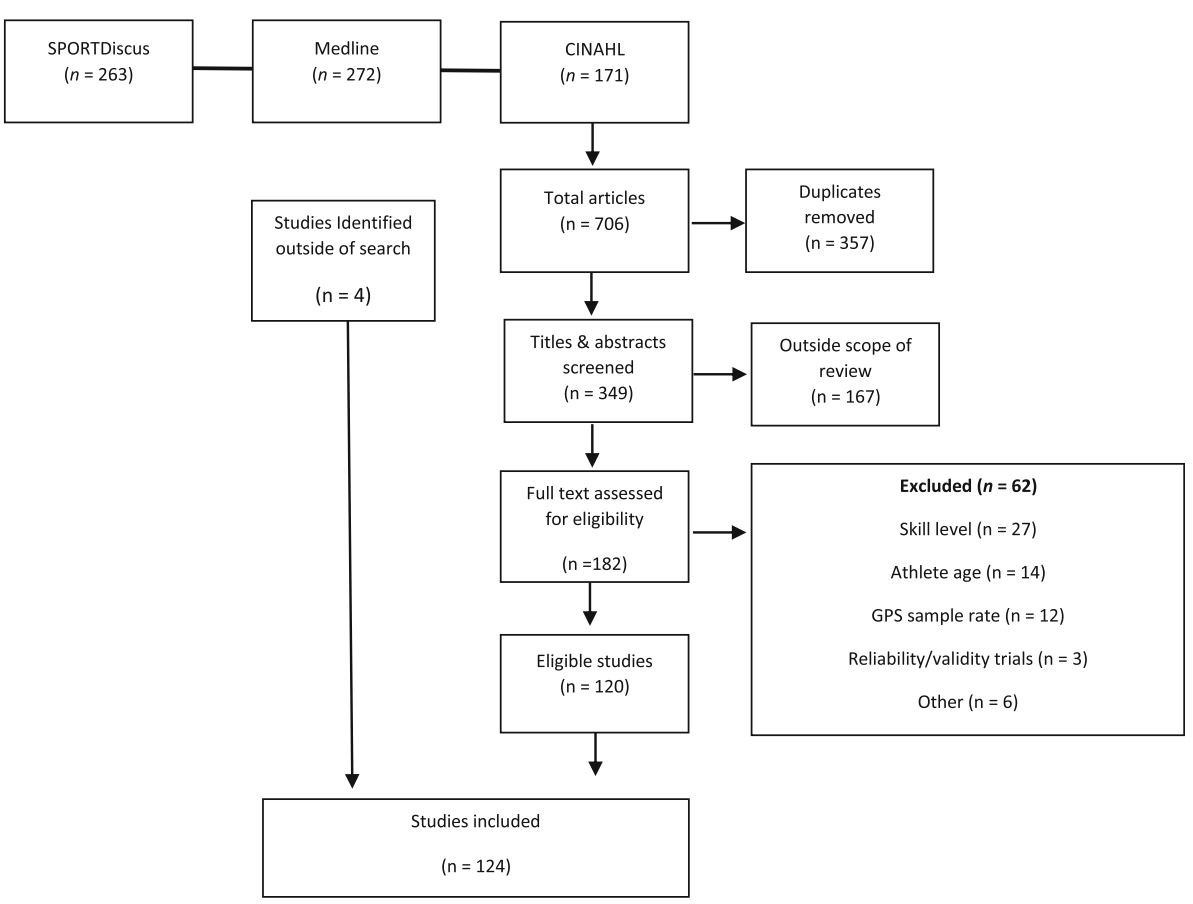

Fig. 1 Systematic review inclusion process for qualification into the review

effort duration of $0.5 \mathrm{~s}$ was most frequent in the included studies, followed by $0.4 \mathrm{~s}, 1 \mathrm{~s}$ and $0.2 \mathrm{~s}$.

\section{Acceleration Metrics}

Acceleration events in this review were quantified via numerous different metrics. These metrics encompassed counts, distance, time, load, intensity and ratio markers. Of these metrics, count-based variables were predominant. Acceleration counts were selected in $72 \%$ of the studies in this review. In total, $63 \%$ of studies included absolute acceleration counts (regardless of magnitude), whilst $32 \%$ of studies implemented acceleration counts relative to the athlete or team's time during the activity (counts per minute). Distance $(\mathrm{m})$ was next highest in terms of prevalence with $13.7 \%$ of the research in this review opting to quantify acceleration events with respect to the distance attained in threshold bands. Metrics of acceleration intensity followed, with a combined $10.9 \%$ of studies (acceleration $\left(\mathrm{m} \mathrm{s}^{-2}\right) 6.7 \%$, deceleration $\left.\left(\mathrm{m} \mathrm{s}^{-2}\right) 4.2 \%\right)$ opting to quantify acceleration with respect to the acceleration distance relative to the time period. Similarly, absolute acceleration was selected in $9.2 \%$ of the included studies for this review. Statistics for the acceleration metrics included are presented in Table 8.

\section{Discussion}

The aim of this systematic review was to outline and compare the different methods that have been adopted to quantify acceleration events in previous team sport research. The main finding in this review was that the vast majority of included studies elected to quantify acceleration events using GPS/GNSS technology (113/124 studies) and via the use of count-based metrics ( $72 \%$ of all studies featured counts). Whilst the aim to ascertain how accelerations were quantified by way of metrics was achieved, this review could not achieve the secondary aim which was to determine how acceleration events were commonly processed in team sport research. Specifically, there was a lack of information provided by the studies in this review that outlined the filtering processes of acceleration events and the minimum effort duration in which these events were designated. In this review, only $13 \%$ of studies specified the filtering settings of their acceleration data whilst 32\% outlined the minimum effort duration. Moreover, for GPS/GNSS research, the reporting of HDOP and the number of satellites was only specified in approximately a quarter of all eligible studies. Given the known influence of data quality metrics, filtering techniques and calculation intervals on acceleration/deceleration as it's calculated, future team sport research should endeavour to outline how acceleration and deceleration events are processed.

\section{Variables Chosen to Quantify Acceleration}

The results of this review overwhelmingly highlight the use of counts to outline the external acceleration load of team sport athletes. Counts and, to a lesser extent, 


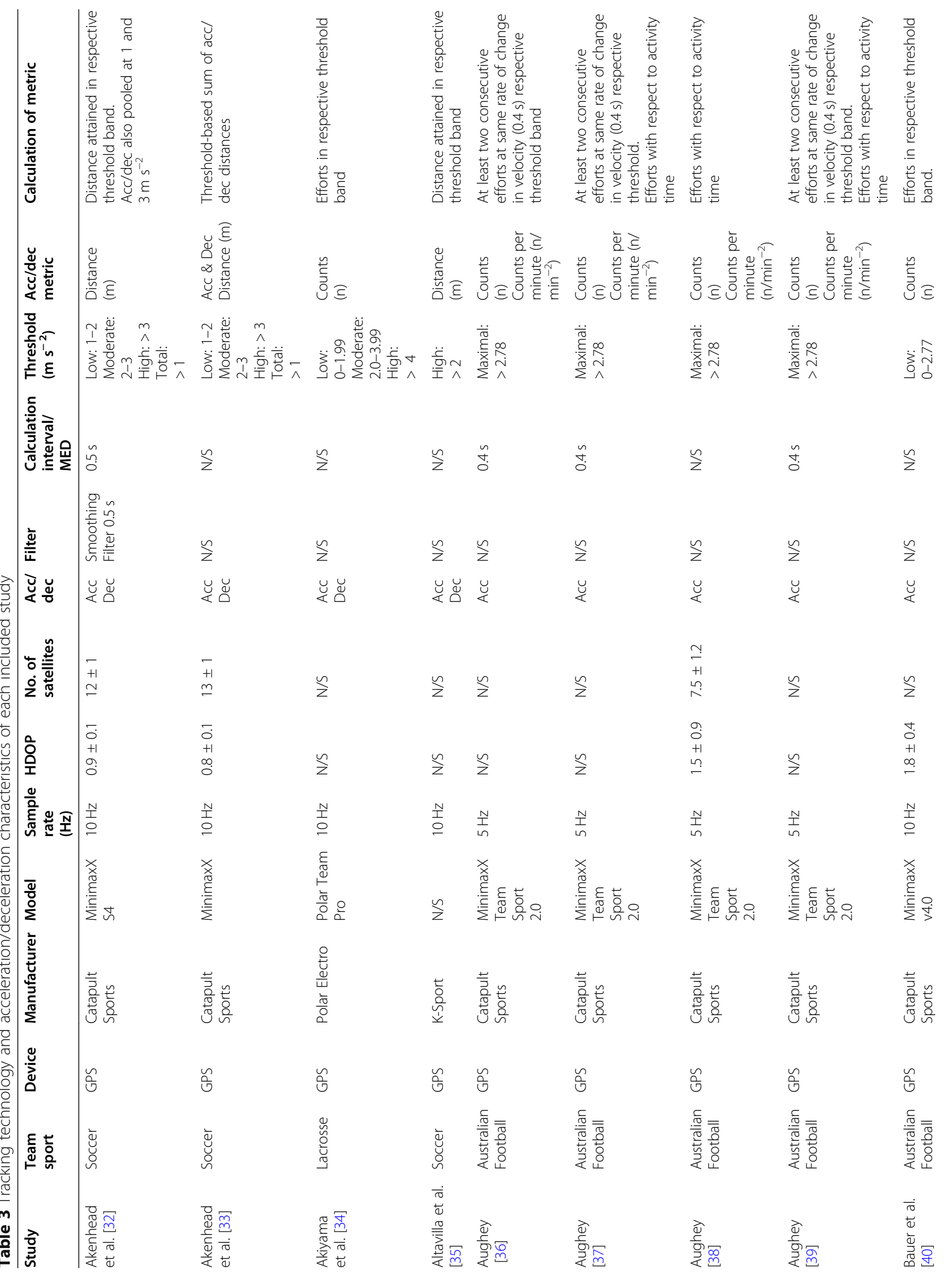




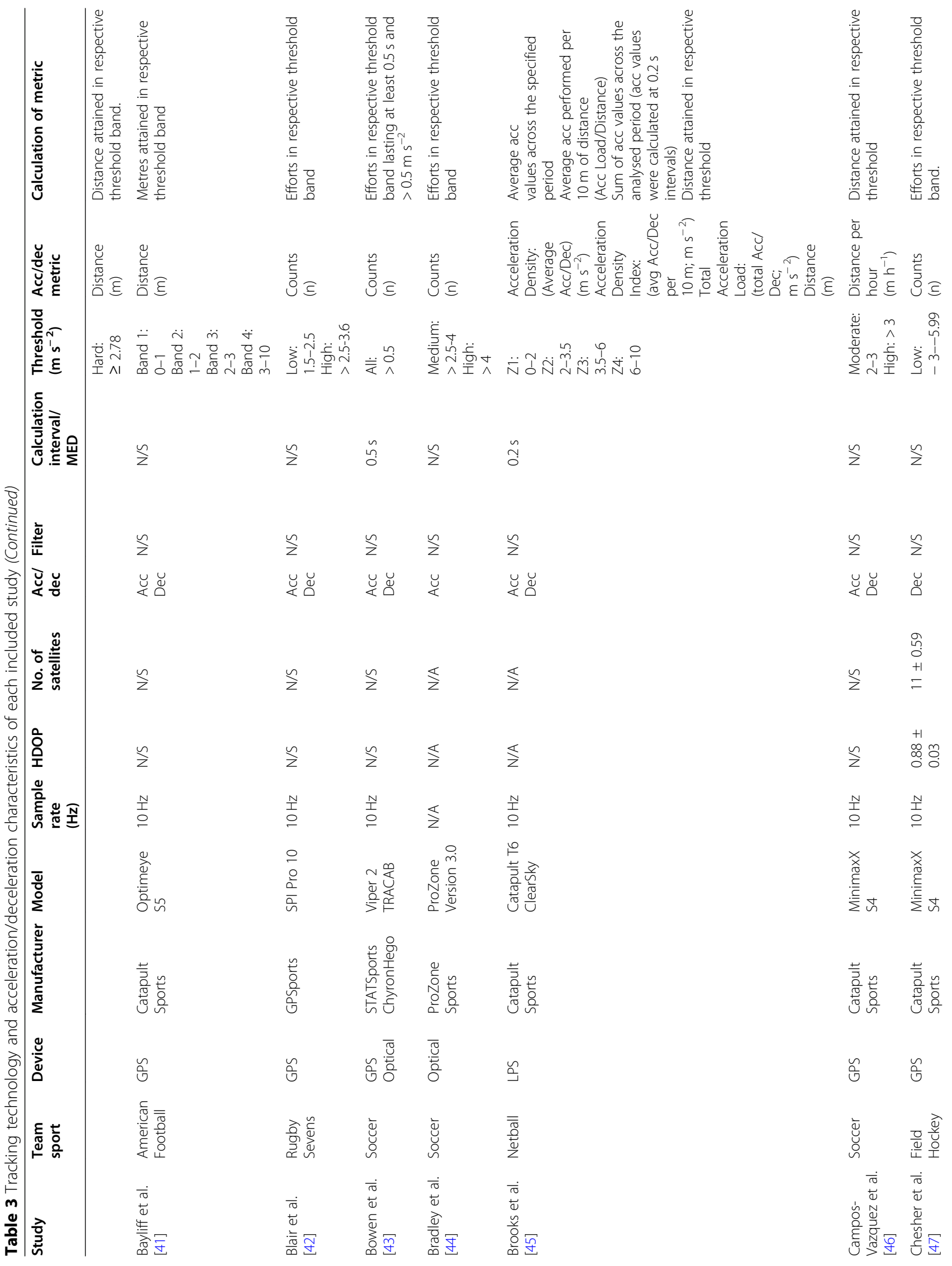




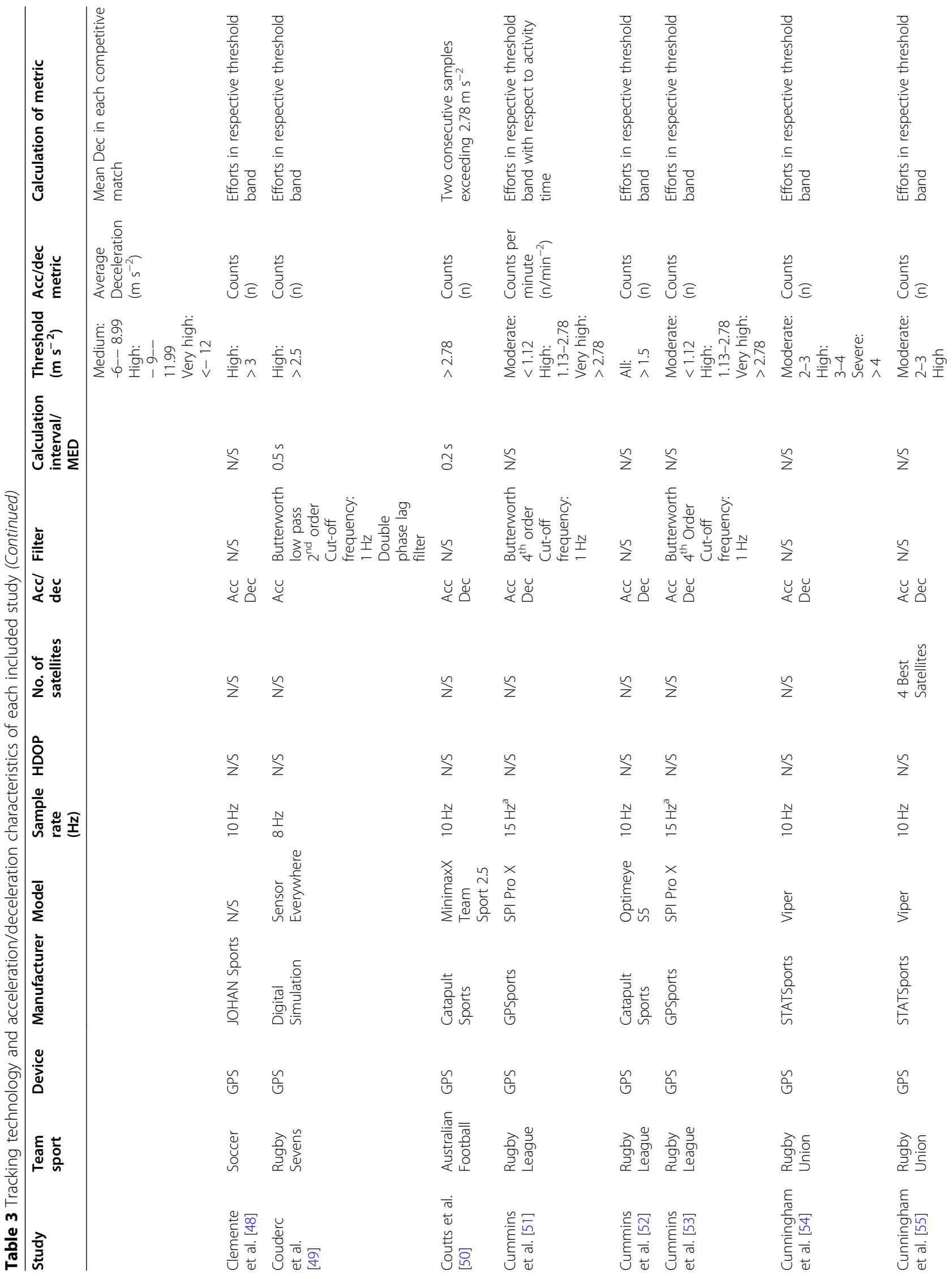




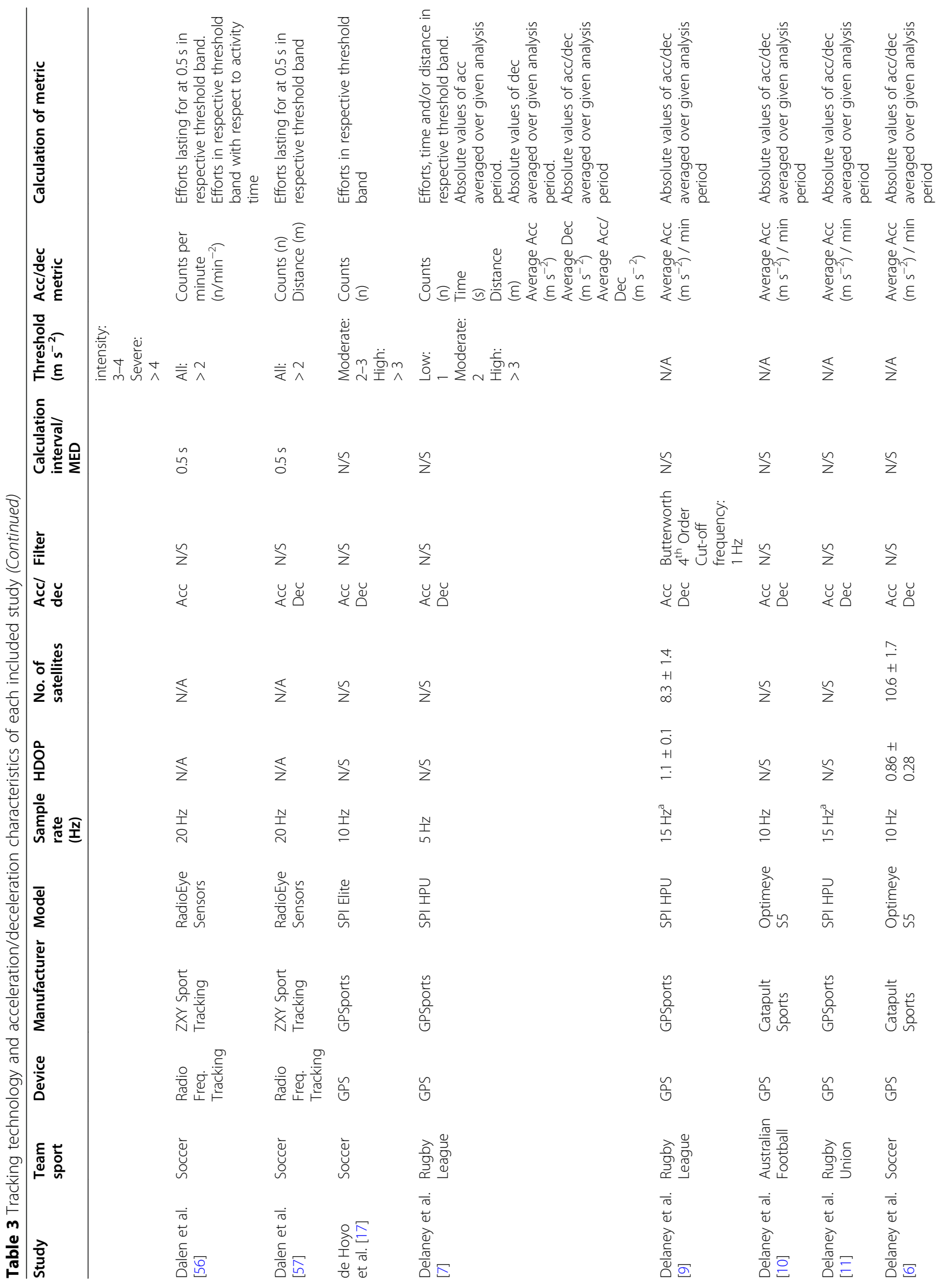




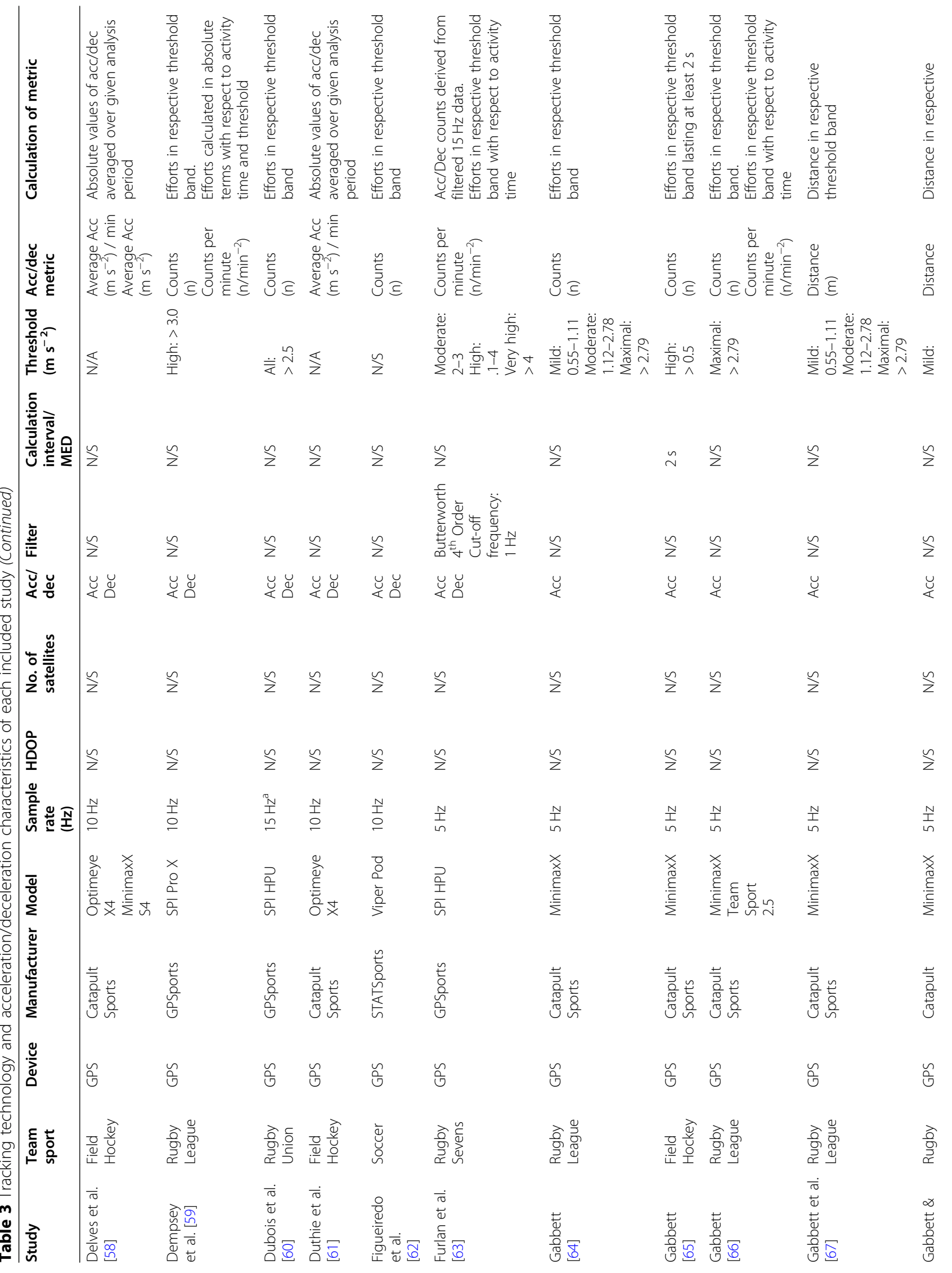




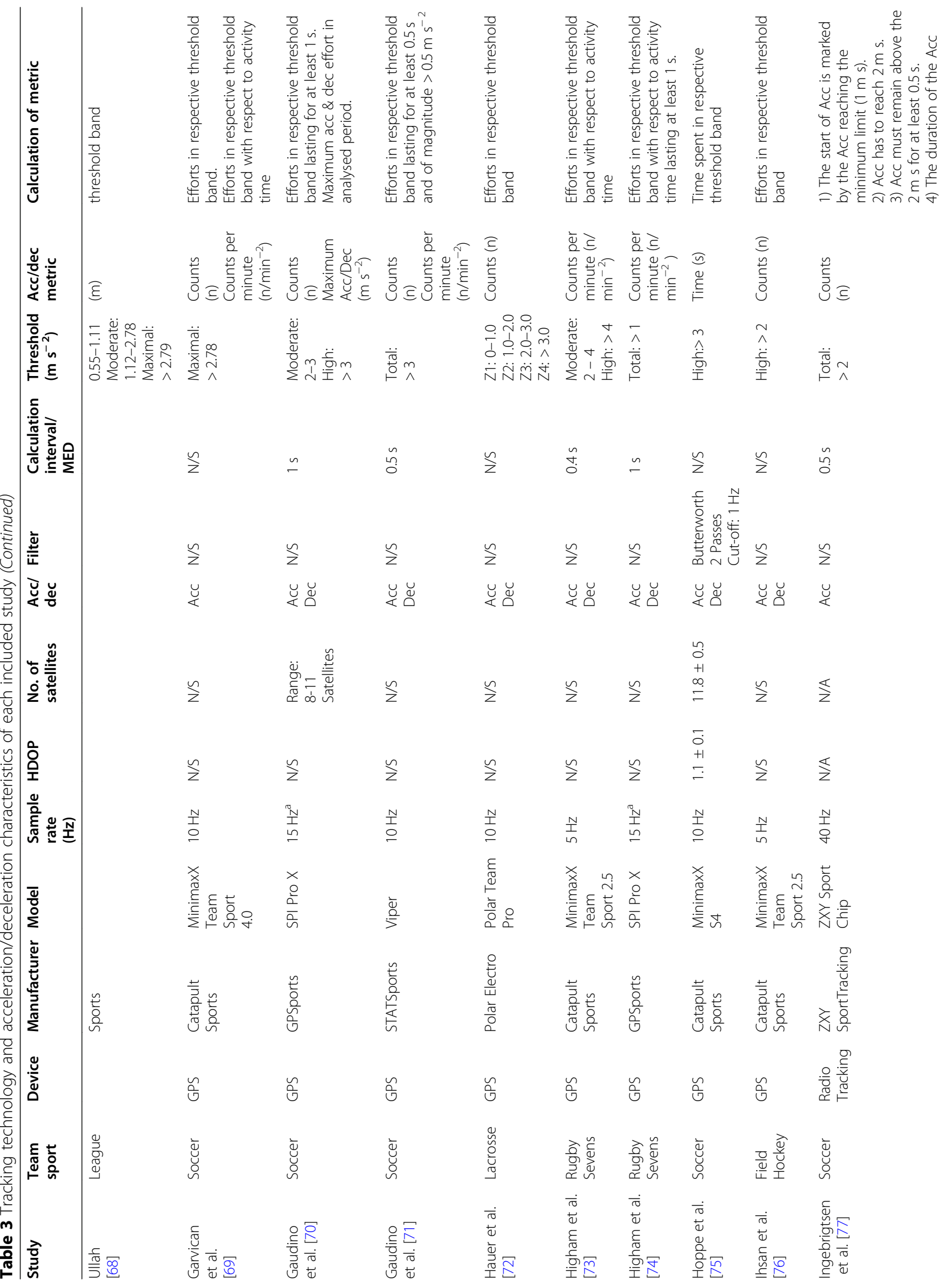




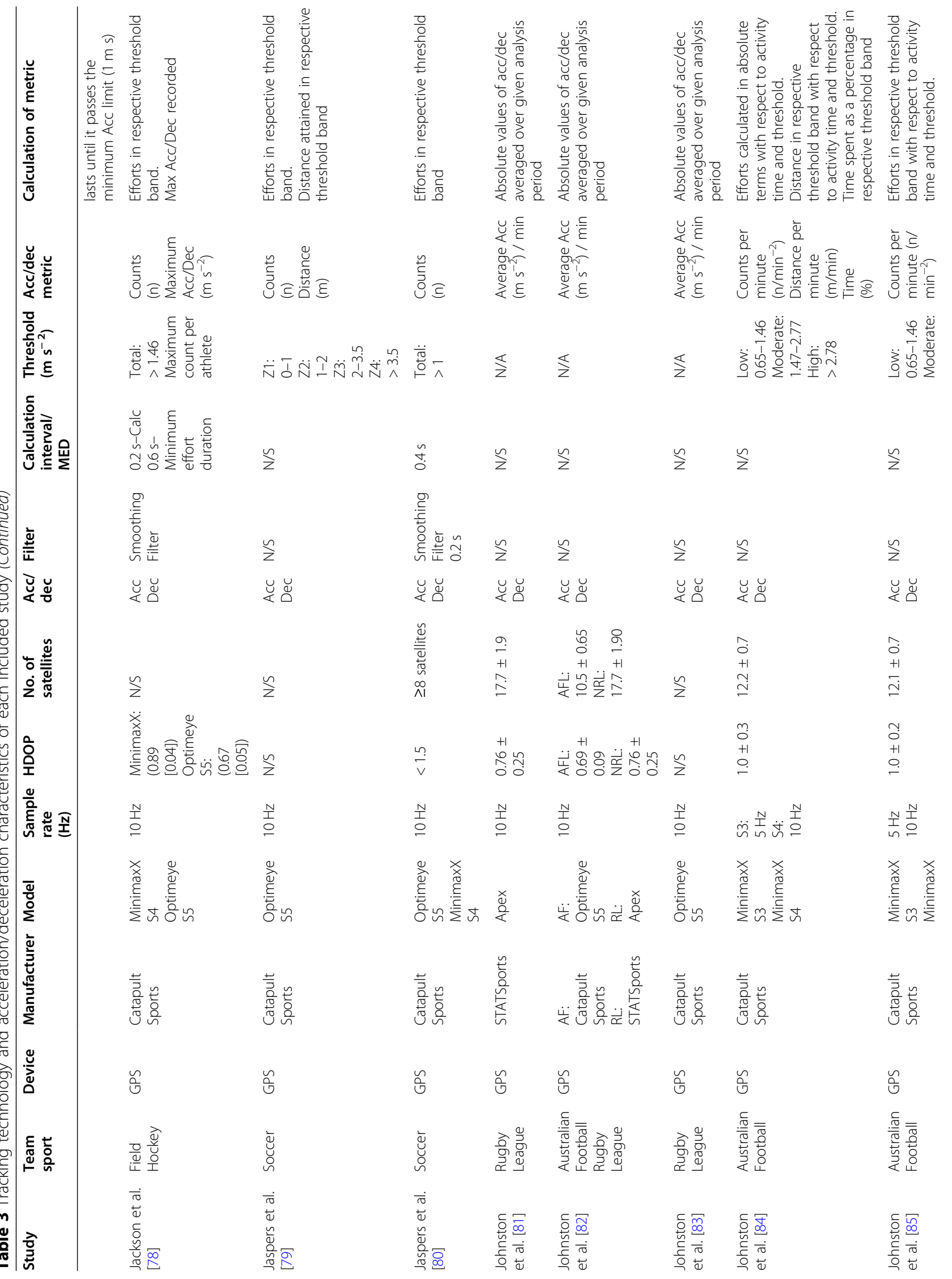


Delves et al. Sports Medicine - Open $\quad$ (2021) 7:45

Page 14 of 35

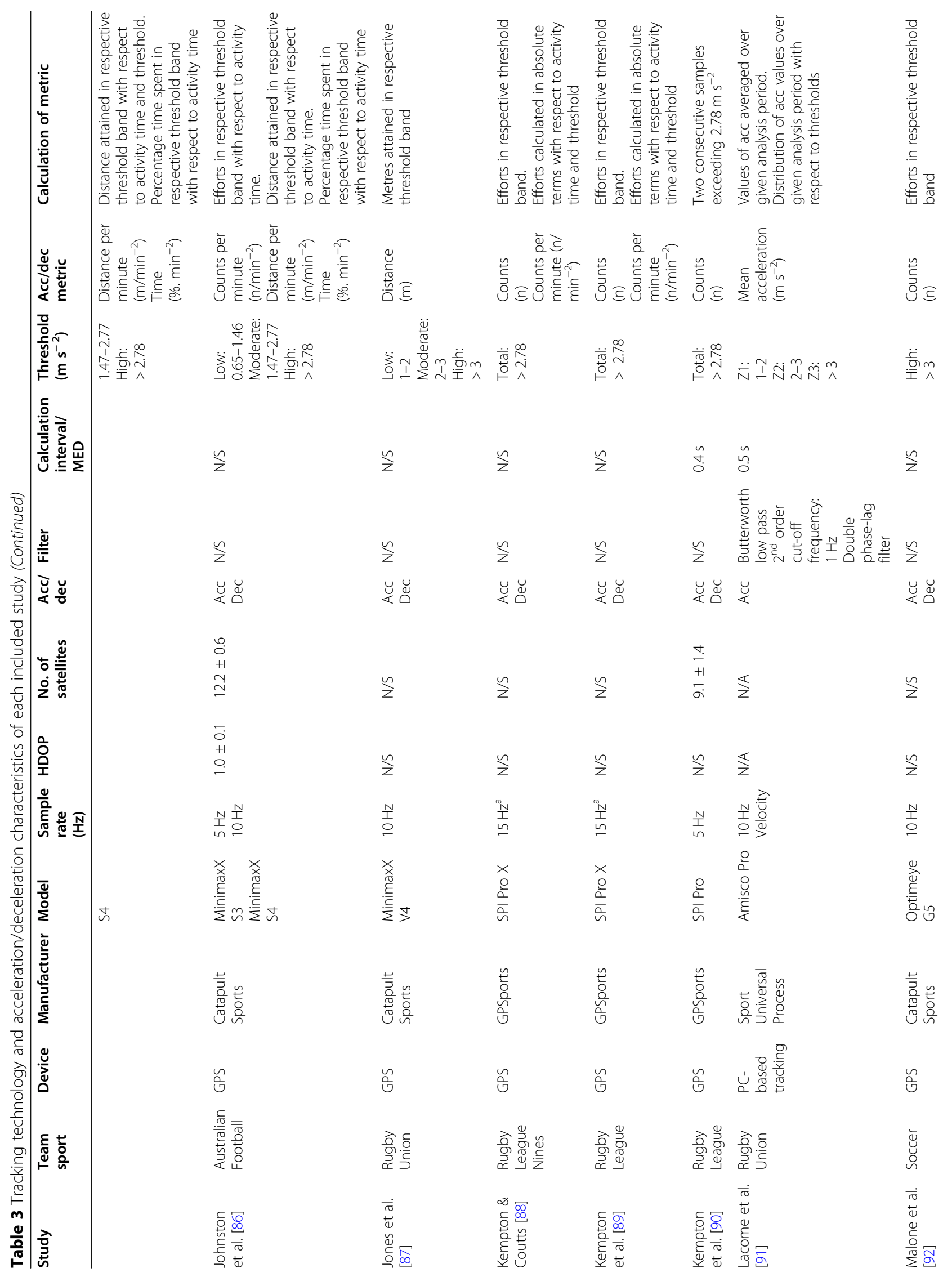




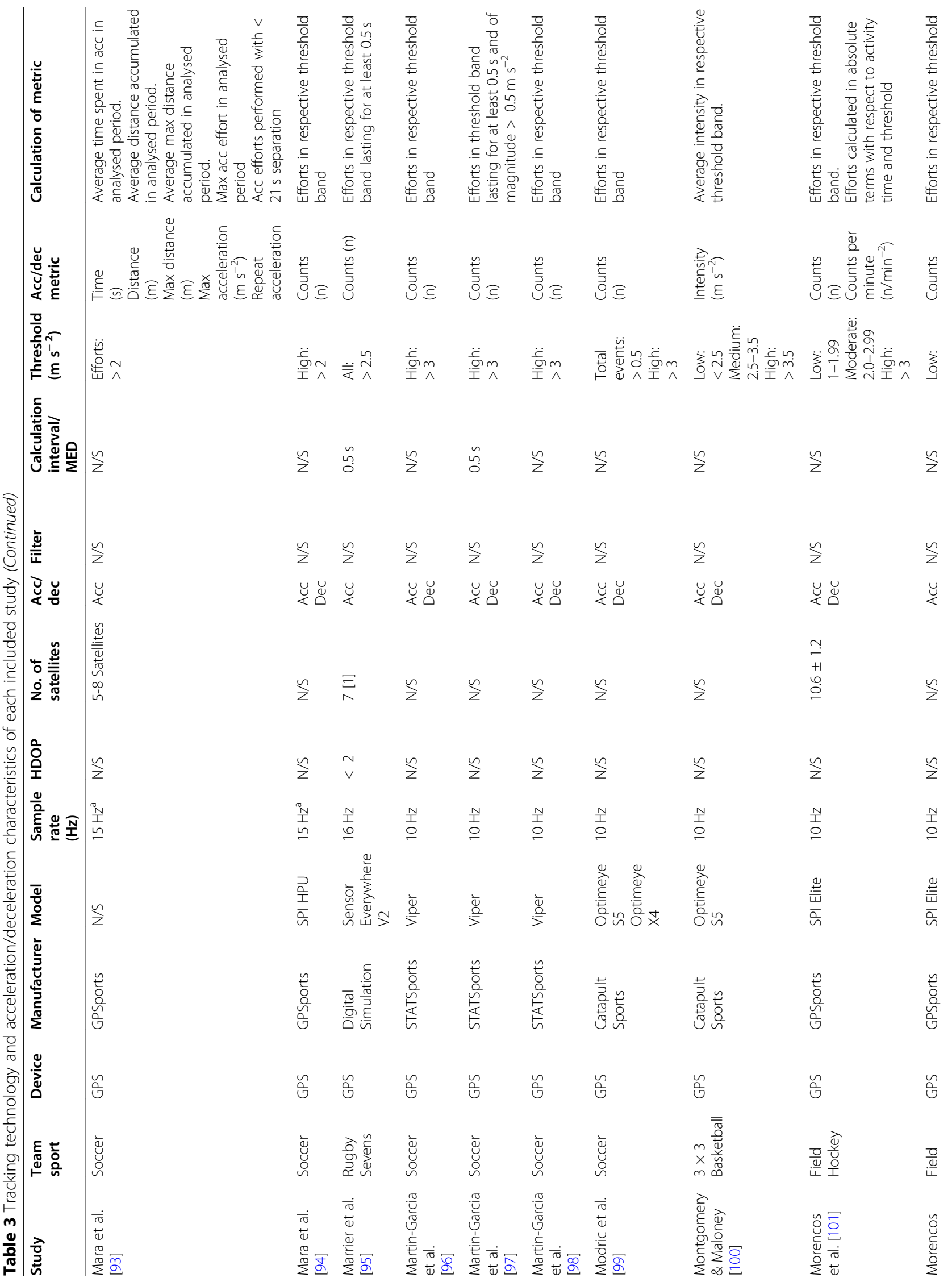




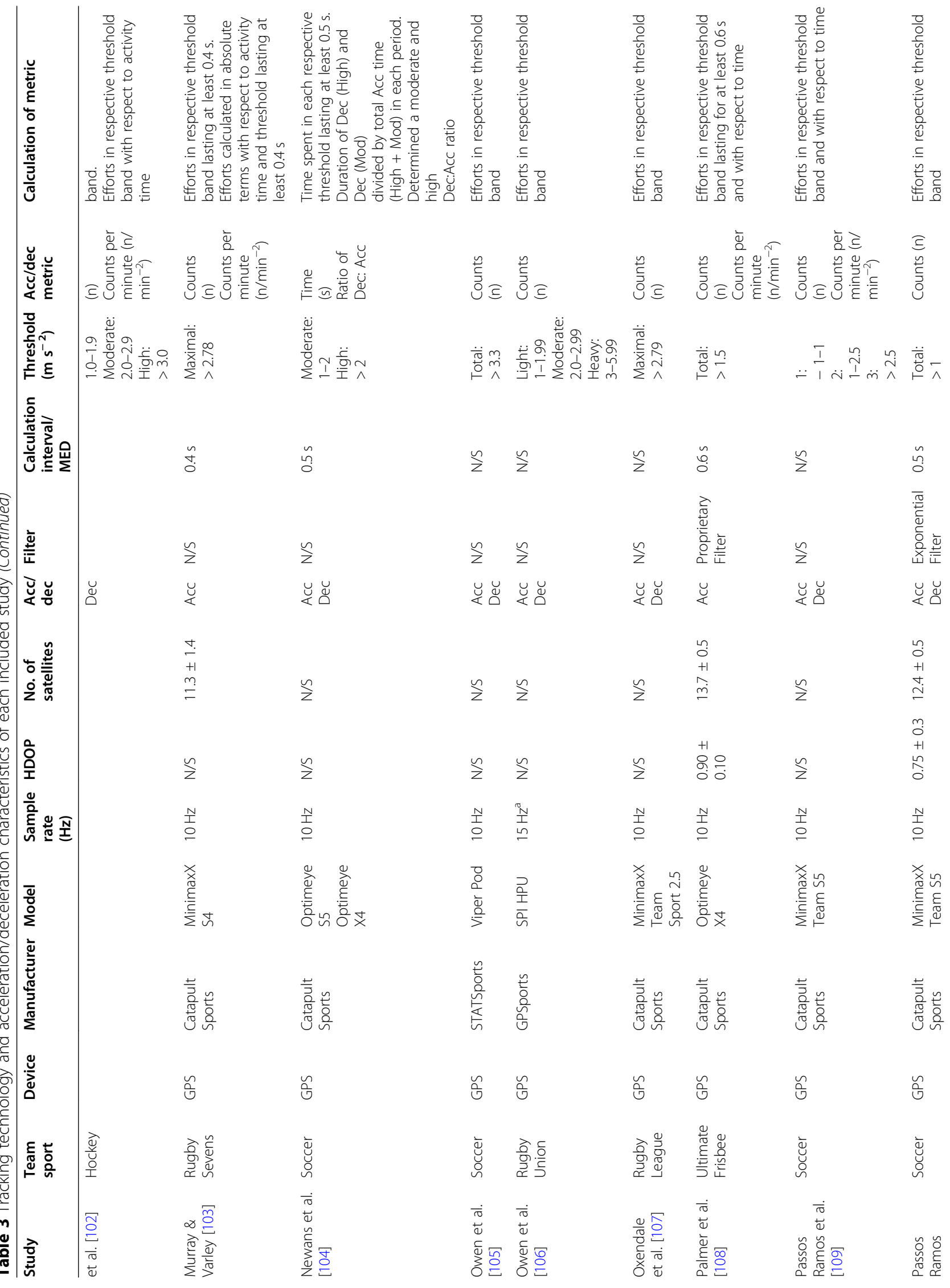




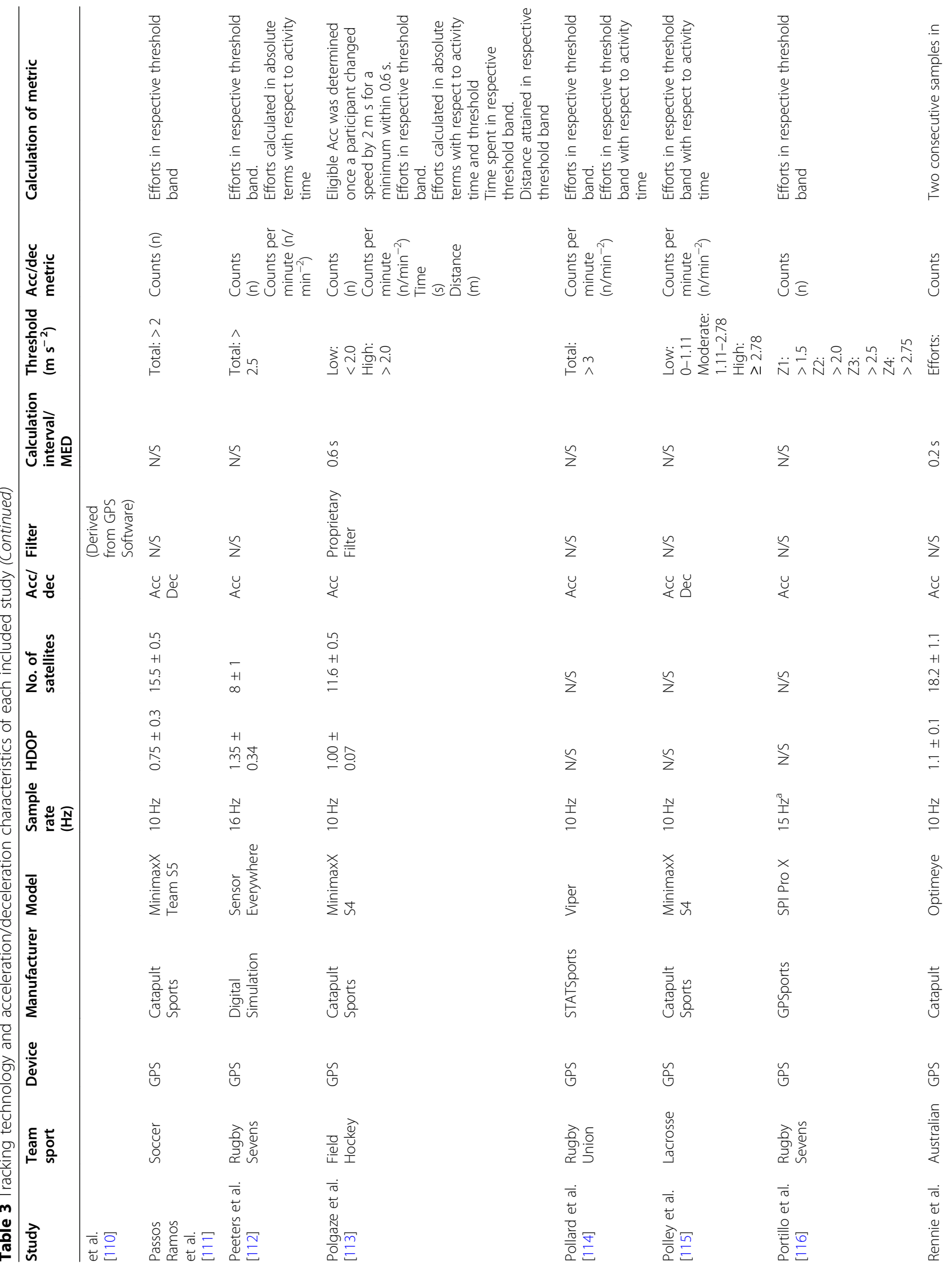




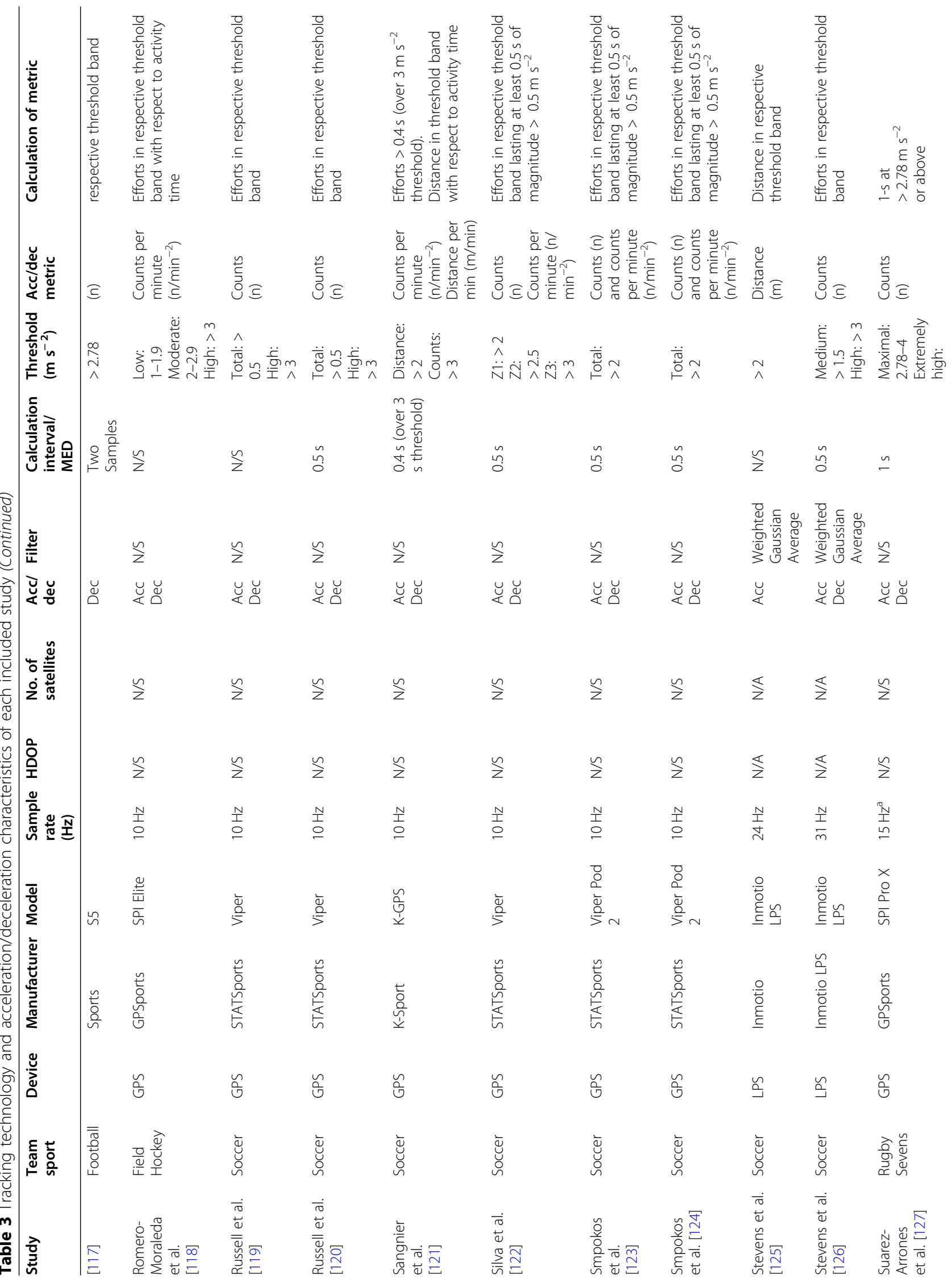




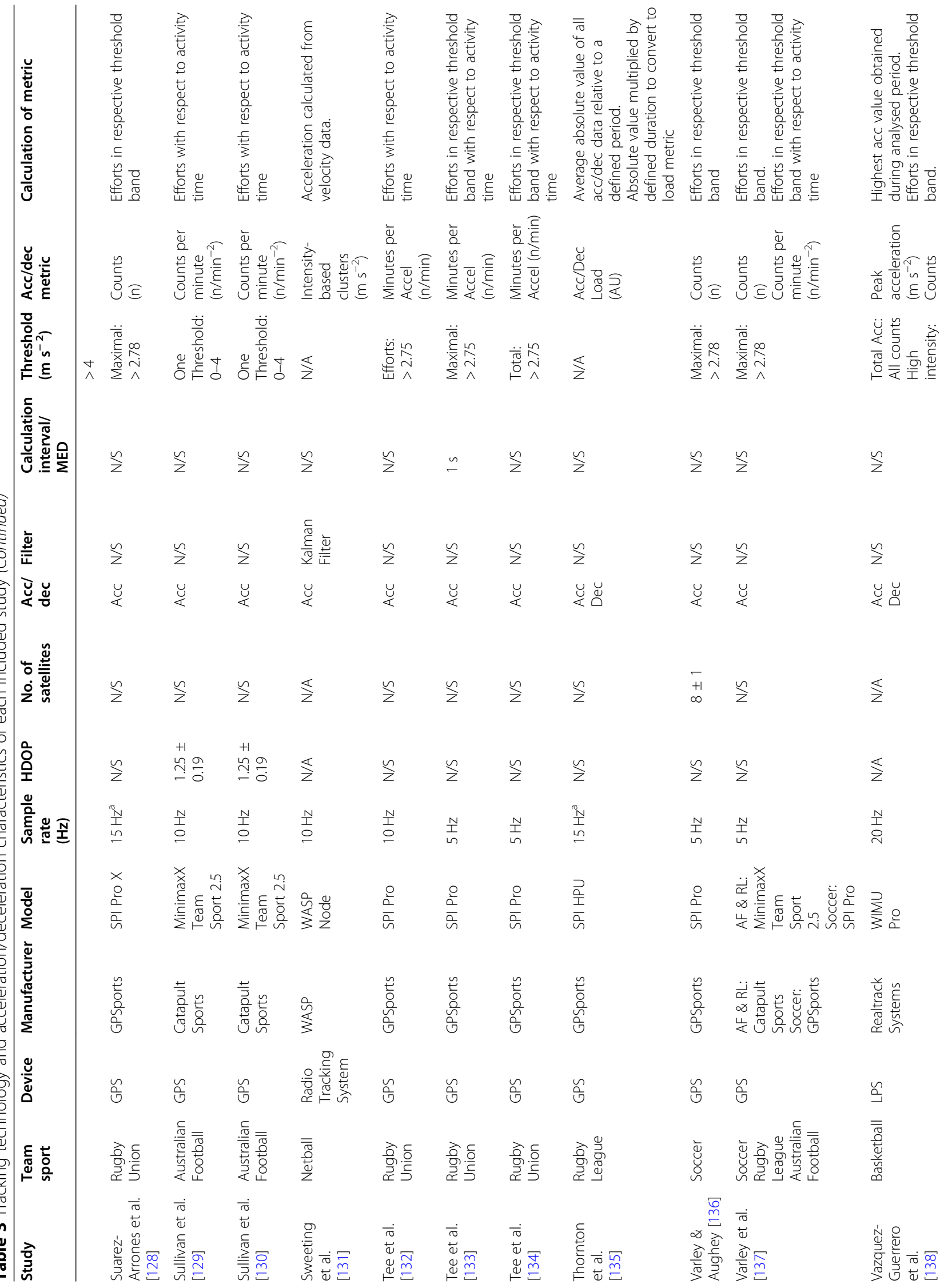




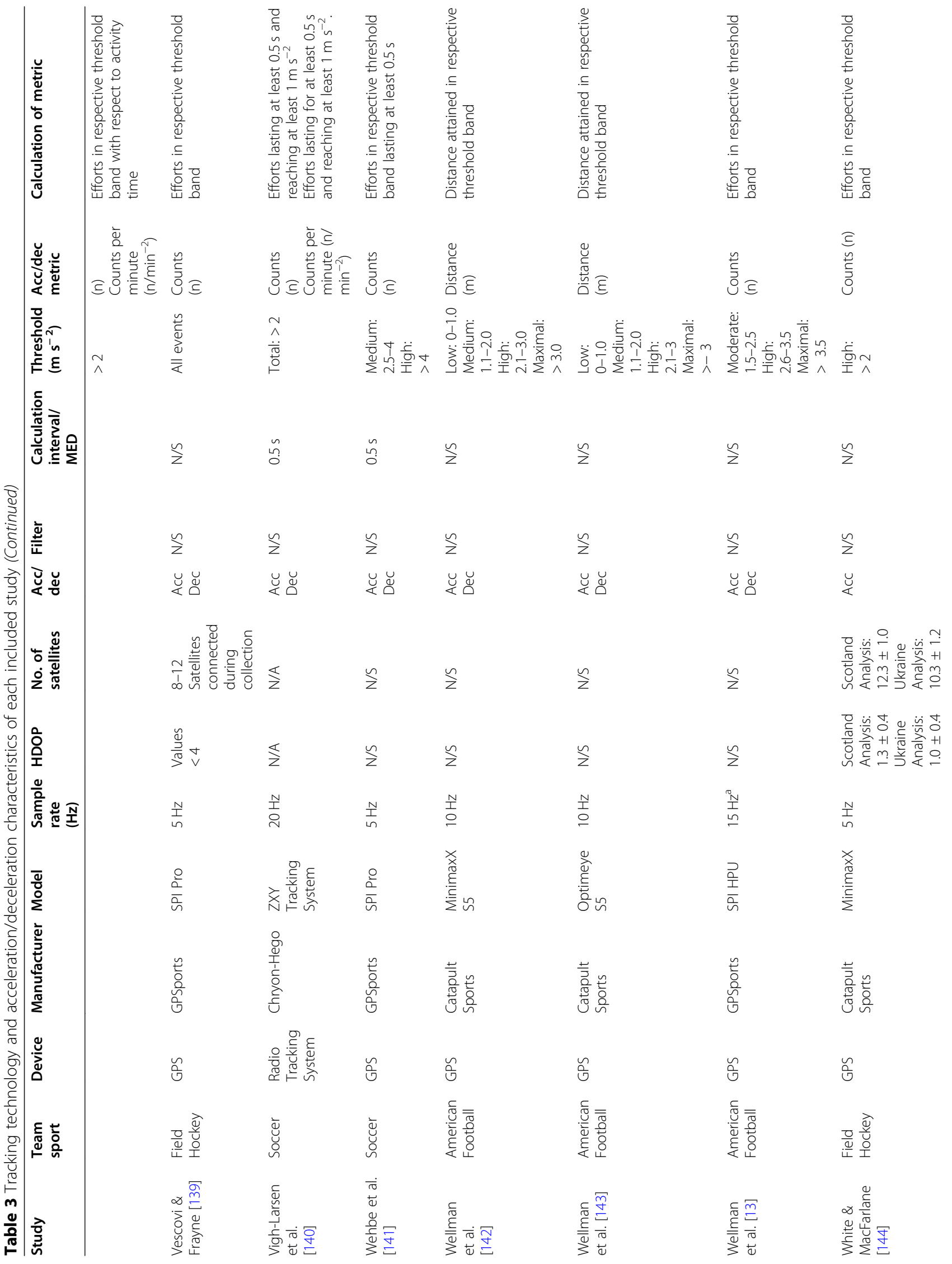




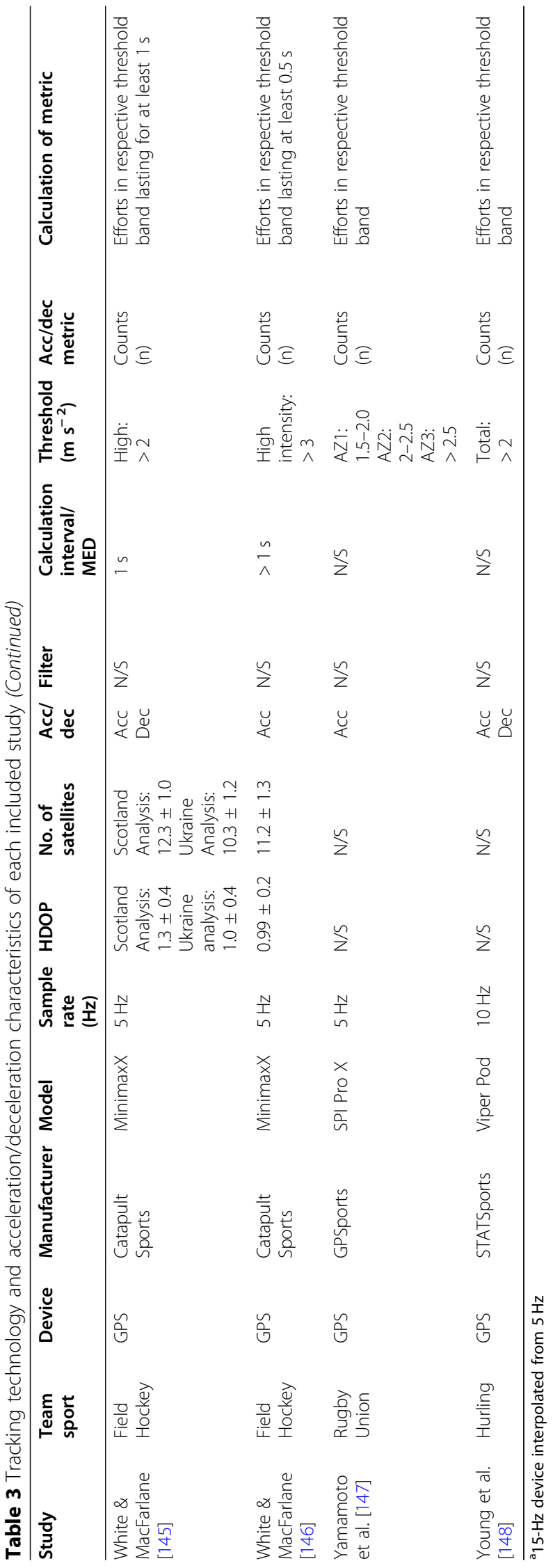


Table 4 Characteristics of studies

\begin{tabular}{|c|c|c|c|c|c|c|}
\hline \multirow[t]{2}{*}{ Sport } & \multirow[t]{2}{*}{$\begin{array}{l}\text { Study } \\
\text { count }\end{array}$} & \multirow{2}{*}{$\begin{array}{l}\% \text { sport } \\
\text { contribution } \\
\text { to review }\end{array}$} & \multicolumn{2}{|c|}{$\begin{array}{l}\text { Study athlete } \\
\text { sex }\end{array}$} & \multirow{2}{*}{ Athlete level } & \multirow[t]{2}{*}{ Reference } \\
\hline & & & $\begin{array}{l}\% \\
\text { Male }\end{array}$ & $\begin{array}{l}\% \\
\text { Female }\end{array}$ & & \\
\hline $\begin{array}{l}3 \times 3 \\
\text { Basketball }\end{array}$ & 1 & 0.8 & 50 & 50 & $\begin{array}{l}\text { Elite, Junior } \\
\text { International }\end{array}$ & [100] \\
\hline $\begin{array}{l}\text { American } \\
\text { Football }\end{array}$ & 4 & 3.1 & 100 & 0 & Elite Collegiate & {$[13,41,142,143]$} \\
\hline $\begin{array}{l}\text { Australian } \\
\text { Football }\end{array}$ & 15 & 11.8 & 100 & 0 & Elite & {$[10,36-40,50,82,84-86,117,129,130,137]$} \\
\hline Basketball & 1 & 0.8 & 100 & 0 & Elite & [138] \\
\hline $\begin{array}{l}\text { Field } \\
\text { Hockey }\end{array}$ & 14 & 11.0 & 66 & 33 & $\begin{array}{l}\text { Elite, Elite } \\
\text { Collegiate }\end{array}$ & {$[47,58,61,65,76,78,101,102,113,118,139,144-146]$} \\
\hline Hurling & 1 & 0.8 & 100 & 0 & Elite & [148] \\
\hline Lacrosse & 3 & 2.4 & 66 & 33 & Elite & {$[34,72,115]$} \\
\hline Netball & 2 & 1.6 & 0 & 100 & Elite & {$[45,131]$} \\
\hline $\begin{array}{l}\text { Rugby } \\
\text { League }\end{array}$ & 18 & 14.2 & 100 & 0 & Elite & {$[7,9,51-53,59,64,66-68,81-83,89,90,107,135,137]$} \\
\hline $\begin{array}{l}\text { Rugby } \\
\text { League } \\
\text { Nines }\end{array}$ & 1 & 0.8 & 100 & 0 & Elite & [88] \\
\hline $\begin{array}{l}\text { Rugby } \\
\text { Sevens }\end{array}$ & 10 & 7.9 & 90 & 10 & Elite & {$[42,49,63,74,95,103,112,116,127]$} \\
\hline $\begin{array}{l}\text { Rugby } \\
\text { Union }\end{array}$ & 13 & 10.2 & 92 & 8 & $\begin{array}{l}\text { Elite, Junior } \\
\text { International }\end{array}$ & {$[11,54,55,60,87,91,106,114,128,132-134,147]$} \\
\hline Soccer & 43 & 33.9 & 88 & 12 & $\begin{array}{l}\text { Elite, Junior } \\
\text { International }\end{array}$ & $\begin{array}{l}{[6,17,32,33,35,43,44,46,48,56,57,62,69-71,75,77,79,80,92-94,96-99,} \\
104,105,109-111,119-126,136,137,140,141]\end{array}$ \\
\hline $\begin{array}{l}\text { Ultimate } \\
\text { Frisbee }\end{array}$ & 1 & 0.8 & 0 & 100 & $\begin{array}{l}\text { Junior } \\
\text { International }\end{array}$ & [108] \\
\hline Total & 127 & 100 & 75 & 25 & & \\
\hline
\end{tabular}

counts relative to time accounted for the vast majority (counts $72 \%$ of all metrics) of acceleration variables selected by team sport researchers. The use of counts is not surprising given the practicality of implementing count-based metrics into the athlete monitoring process. Counts are advantageous to the practitioner for a number of reasons. Firstly, this is due to the ability to detail the number of actions occurring, usually with respect to particular thresholds. The volume of counts provides an indication of the total acceleration load and, when coupled with activity time of the athlete, can also provide an indication of the acceleration intensity. Secondly, it is relatively simple for a practitioner to apply thresholds to count metrics via the manufacturer proprietary software. This simplicity allows for efficient processing and analysis of the external acceleration load of the athlete or team.

In isolation, outlining external acceleration load via counts is an acceptable choice for most researchers and practitioners. However, counts are regularly implemented in conjunction with velocity-based thresholds that may separate efforts into corresponding bands [8].
Despite the use of threshold bands being a common practice in applied sport science, this method is limited by the validity and reliability of the athlete-tracking system recording the event [7]. Specifically, threshold-based counts for accelerations have been set at discrete intervals which may separate counts from being moderate or high with small differences separating the bands. For example, Bauer et al. [40] presented external acceleration load using count thresholds of $0-2.77 \mathrm{~m} \mathrm{~s}^{-2}$ (low) and > $2.78 \mathrm{~m} \mathrm{~s}^{-2}$ (high). Similarly, Blair et al. [42] specified low acceleration counts at $1.5-2.5 \mathrm{~m} \mathrm{~s}^{-2}$ and high counts at $>2.5 \mathrm{~m} \mathrm{~s}^{-2}$. Whilst it is logical to define a lower and upper threshold for each band, counts are also influenced by the level of error in the wearable technology device [7, 26]. For example, in Buchheit et al. [149], large inter-unit variations were found between GPS devices in acceleration and deceleration counts (coefficient of variation (CV) 10-56\%) during a team sport movement simulation [7]. Following on from the research in Buchheit et al. [149], Delaney et al. [7] raised the issue that the variation seen in the aforementioned study could have been a result of the use of threshold-based counts. 
Table 5 Tracking system characteristics

\begin{tabular}{|c|c|c|c|c|}
\hline Tracking technology & Manufacturer & Device & Sample rate & Reference \\
\hline \multicolumn{5}{|c|}{ Global Positioning System/Global Navigation Satellite System } \\
\hline \multirow[t]{15}{*}{ GPS } & Catapult Sports & Optimeye S5 & $10 \mathrm{~Hz}$ & {$[6,10,41,52,78-80,82,83,99,100,104,117,143]$} \\
\hline & & Optimeye G5 & $10 \mathrm{~Hz}$ & [92] \\
\hline & & Optimeye X4 & $10 \mathrm{~Hz}$ & {$[58,61,99,104,108]$} \\
\hline & & MinimaxX S5 & $10 \mathrm{~Hz}$ & {$[109-111,142]$} \\
\hline & & MinimaxX S4 & $10 \mathrm{~Hz}$ & {$[32,46,47,58,75,78,80,84-86,103,113,115]$} \\
\hline & & MinimaxX S3 & $5 \mathrm{~Hz}$ & [84-86] \\
\hline & & MinimaxX Team Sport 2.0 & $5 \mathrm{~Hz}$ & [36-39] \\
\hline & & MinimaxX Team Sport 2.5 & $5 \mathrm{~Hz}$ & {$[66,73,76,137]$} \\
\hline & & & $10 \mathrm{~Hz}$ & {$[50,107,129,130]$} \\
\hline & & MinimaxX Team Sport 4.0 & $10 \mathrm{~Hz}$ & {$[40,69,87]$} \\
\hline & & MinimaxX & $5 \mathrm{~Hz}$ & {$[64,65,67,68,144-146]$} \\
\hline & & & $10 \mathrm{~Hz}$ & [33] \\
\hline & STATSports & APEX & $10 \mathrm{~Hz}$ & {$[81,82]$} \\
\hline & & Viper & $10 \mathrm{~Hz}$ & {$[54,55,62,71,96-98,105,114,119,120,122,148]$} \\
\hline & & Viper 2 & $10 \mathrm{~Hz}$ & {$[43,123,124]$} \\
\hline \multirow[t]{11}{*}{ GPS } & GPSports & SPI Elite & $10 \mathrm{~Hz}$ & {$[17,101,102,118]$} \\
\hline & & SPI HPU & $15 \mathrm{~Hz}^{\mathrm{a}}$ & {$[7,9,11,13,60,63,94,106,135]$} \\
\hline & & SPI Pro & $5 \mathrm{~Hz}$ & {$[90,133,134,136,137,139,141]$} \\
\hline & & & $10 \mathrm{~Hz}$ & {$[42,132]$} \\
\hline & & SPI Pro $X$ & $15 \mathrm{~Hz}^{\mathrm{a}}$ & {$[51,70,74,88,89,116,127,128,147]$} \\
\hline & & & $10 \mathrm{~Hz}$ & [59] \\
\hline & Polar & Polar Team Pro & $10 \mathrm{~Hz}$ & {$[34,72]$} \\
\hline & Digital Simulation & SensorEverywhere & $8 \mathrm{~Hz}$ & [49] \\
\hline & & & $16 \mathrm{~Hz}$ & {$[95,112]$} \\
\hline & JOHAN Sports & Johan GPS & $10 \mathrm{~Hz}$ & {$[48]$} \\
\hline & K-Sport & K-GPS & $10 \mathrm{~Hz}$ & {$[35,121]$} \\
\hline \multicolumn{5}{|l|}{ Local positioning systems } \\
\hline \multirow[t]{4}{*}{ LPS } & Catapult Sports & ClearSky T6 & $10 \mathrm{~Hz}$ & {$[45]$} \\
\hline & Realtrack Systems & WIMU Pro & $20 \mathrm{~Hz}$ & [138] \\
\hline & Inmotio & Inmotio LPM & $24 \mathrm{~Hz}$ & {$[125]$} \\
\hline & & Inmotio LPM & $31 \mathrm{~Hz}$ & {$[126]$} \\
\hline \multicolumn{5}{|l|}{ Radio frequency } \\
\hline \multirow[t]{3}{*}{ Radio frequency } & Chyron Hego & ZXY Tracking System & $40 \mathrm{~Hz}$ & [77] \\
\hline & & ZXY Tracking System & $20 \mathrm{~Hz}$ & {$[56,57,140]$} \\
\hline & WASP & WASP Node & $10 \mathrm{~Hz}$ & [131] \\
\hline \multicolumn{5}{|l|}{ Optical } \\
\hline \multirow[t]{3}{*}{ Optical-based tracking } & ProZone Sports & ProZone 3.0 & $N / S$ & [44] \\
\hline & $\begin{array}{l}\text { Sport } \\
\text { Universal Process }\end{array}$ & Amisco Pro & $25 \mathrm{~Hz}$ & [91] \\
\hline & Chyron Hego & TRACAB & $N / S$ & [43] \\
\hline
\end{tabular}

${ }^{\mathrm{a}} 15-\mathrm{Hz}$ device interpolated from $5 \mathrm{~Hz}$ 
Table 6 GPS/GNSS data quality metrics of included studies

\begin{tabular}{|c|c|c|c|c|}
\hline $\begin{array}{l}\text { GPS/GNSS } \\
\text { Data quality metric }\end{array}$ & $\begin{array}{l}\text { Unit of } \\
\text { measure }\end{array}$ & $\begin{array}{l}\text { Studies that } \\
\text { outlined variable }\end{array}$ & $\begin{array}{l}\% \text { of studies in review that } \\
\text { outlined information }\end{array}$ & Reference \\
\hline $\begin{array}{l}\text { Horizontal Dilution of } \\
\text { Precision (HDOP) }\end{array}$ & $\begin{array}{l}\text { Mean } \pm \\
\text { SD }\end{array}$ & $27 / 113$ & $23.9 \%$ & $\begin{array}{l}{[6,9,32,33,38,40,47,75,78,81,82,84-86,95,108,110-} \\
113,117,120,129,130,139,144-146]\end{array}$ \\
\hline $\begin{array}{l}\text { Number of satellites } \\
\text { connected }\end{array}$ & $\begin{array}{l}\text { Mean } \pm \\
\text { SD }\end{array}$ & $31 / 113$ & $27.4 \%$ & $\begin{array}{l}{[6,9,32,33,38,47,55,70,75,80-82,84-86,90,93,95,101,} \\
103,108,110-113,117,120,136,139,144-146]\end{array}$ \\
\hline
\end{tabular}

Specifically, the use of discrete bands for count-based acceleration events was suggested to be subject to the device reliability and that the cut-off threshold could then be subject to between-device variation. Using the example provided by Delaney et al. [7], a $3 \mathrm{~m} \mathrm{~s}^{-2}$ cut-off could be measured differently by two different tracking devices. One device may measure the event at $2.98 \mathrm{~m}$ $\mathrm{s}^{-2}$, which would not qualify for the cut-off, whilst the other may measure the effort at $3.01 \mathrm{~m} \mathrm{~s}^{-2}$, which would constitute an event. It is then problematic if one device records the effort as an event, whilst the other does not, which may create inconsistencies in both the literature and the athlete monitoring process.

Issues surrounding the reliability of threshold-based variables also apply to the acceleration metrics that are measured in terms of distance (metres). Outside of the count-based metrics, distance-based acceleration variables were the third most frequent ( $18 \%$ combined) metric implemented by the included studies in this review. Despite sharing similar advantages to the use of count variables, distance-based metrics are also susceptible to similar issues of inter-unit reliability, particularly at moderate to high acceleration thresholds. In Thornton et al. [26], a team sport simulation circuit was implemented to identify the inter-unit reliability for three commercially available GPS/GNSS devices. For acceleration metrics, software-derived, moderate acceleration distance for STATSports APEX units were classified as having poor reliability (CV; $90 \%$ confidence limit 19.7\%; $\pm 1.5 \%)$ whilst GPSports EVO (2.7\%; $\pm 1.5 \%)$ and
Catapult Sports S5 $(3.1 \%$; $\pm 1.6 \%)$ devices showed greater reliability. The substantial variation seen across the results of the three GPS/GNSS devices highlights the potential issues associated with threshold-based variables of acceleration metrics as measured by athlete-tracking devices [26]. Moreover, interchanging tracking/positional systems (e.g., GNSS \& LPS) can also provide reliability issues between technologies for practitioners and researchers [150]. Given the increased use of LPS and camera-based systems within outdoor stadiums, practitioners may need to change between technologies depending on their training and competition locations [26]. Research from Buchheit et al. [150] highlighted small to very large variation from one LPM system (Inmotio) against GPS (GPSports SPI Pro XII \& VX VX340a) and a semi-automated camera system across acceleration efforts $\left(>3 \mathrm{~m} \mathrm{~s}^{-2}\right)$ during match play analysis of the study. With the results of the aforementioned study, any variability between tracking systems may then have practical implications for practitioners. Generally, athletes complete the same team drills and therefore have an expectation surrounding the respective external loads associated with those drills.

A suggested way to alleviate the concerns with interunit variability in count-based approaches is to assign a wearable tracking device to an athlete for the duration of the competitive season $[7,151]$. Whilst this suggestion is important to maintain consistency in the load reporting for each athlete, it is not without limitation. The wearable tracking device may consistently measure under the

Table 7 Acceleration characteristics of included studies

\begin{tabular}{|c|c|c|c|c|c|}
\hline $\begin{array}{l}\text { Acceleration/deceleration } \\
\text { calculation metric }\end{array}$ & $\begin{array}{l}\text { Unit of } \\
\text { measure }\end{array}$ & $\begin{array}{l}\text { Minimum effort } \\
\text { duration }\end{array}$ & $\begin{array}{l}\text { Outlined in } \\
\text { studies }\end{array}$ & $\begin{array}{l}\% \text { of studies } \\
\text { in review }\end{array}$ & Reference \\
\hline Velocity or acceleration filter & N/A & N/A & $16 / 124$ & $12.9 \%$ & $\begin{array}{l}{[9,32,49,51,53,63,75,78,80,91,108,110,113,} \\
125,126,131]\end{array}$ \\
\hline \multirow{7}{*}{$\begin{array}{l}\text { Minimum effort duration/ } \\
\text { calculation interval }\end{array}$} & Seconds (s) & $0.2 \mathrm{~s}$ & & & {$[45,50,117]$} \\
\hline & & $0.4 \mathrm{~s}$ & & & {$[36,37,39,73,80,90,103,121]$} \\
\hline & & $0.5 \mathrm{~s}$ & & & $\begin{array}{l}{[32,43,49,56,57,71,77,91,95,97,104,110,} \\
120,122-124,126,140,141]\end{array}$ \\
\hline & & $0.6 \mathrm{~s}$ & & & {$[78,108,113]$} \\
\hline & & $1 \mathrm{~s}$ & & & {$[70,74,127,133,145,146]$} \\
\hline & & $2 \mathrm{~s}$ & & & [65] \\
\hline & & Total & $40 / 124$ & $32.3 \%$ & \\
\hline
\end{tabular}


Table 8 Acceleration metrics of included studies

\begin{tabular}{|c|c|c|c|c|}
\hline $\begin{array}{l}\text { Acceleration/ } \\
\text { deceleration } \\
\text { metric }\end{array}$ & $\begin{array}{l}\text { Unit of } \\
\text { measure }\end{array}$ & Metric definition & $\begin{array}{l}\% \text { of } \\
\text { studies } \\
\text { featuring } \\
\text { metric }\end{array}$ & Reference \\
\hline \multirow[t]{3}{*}{ Counts } & $\begin{array}{l}\text { Counts } \\
\text { (number) }\end{array}$ & Efforts in respective threshold band & $62.9 \%$ & \multirow{3}{*}{$\begin{array}{l}{[7,13,17,34,36-40,42-44,47-50,52,54,55,57,59,60,62,} \\
64-66,69-72,76-80,88-90,92,94-99,101-103,105-113, \\
116,117,119,120,122-124,126-128,136-141,144-148] \\
{[36-39,51,53,56,59,63,66,69,71,73,74,84-86,88,89,} \\
101-103,108,109,112-115,118,121-124,129,130,137,138 \\
140]\end{array}$} \\
\hline & $\begin{array}{l}\text { Counts } \\
\text { (number) } \\
\text { per minute }\end{array}$ & $\begin{array}{l}\text { Efforts in respective threshold band with } \\
\text { respect to activity time }\end{array}$ & $31.7 \%$ & \\
\hline & $\begin{array}{l}\text { Counts } \\
\text { (absolute } \\
\text { and relative) }\end{array}$ & $\begin{array}{l}\text { Overall absolute and relative count } \\
\text { contribution to review }\end{array}$ & $71.8 \%$ & \\
\hline \multirow[t]{3}{*}{ Distance } & Metres & $\begin{array}{l}\text { Acc/Dec distance attained in respective } \\
\text { threshold band }\end{array}$ & $13.7 \%$ & $\begin{array}{l}{[7,32,33,35,40,41,45,57,67,68,79,87,93,113,125,142,} \\
143]\end{array}$ \\
\hline & Per minute & $\begin{array}{l}\text { Distance in respective threshold band } \\
\text { with respect to activity time and } \\
\text { threshold }\end{array}$ & $3.3 \%$ & {$[84-86,121]$} \\
\hline & Per hour & $\begin{array}{l}\text { Distance attained in respective } \\
\text { threshold band }\end{array}$ & $0.8 \%$ & {$[46]$} \\
\hline Acceleration & $\mathrm{ms}^{-2}$ & $\begin{array}{l}\text { Intensity metric of any magnitude of } \\
\text { acc over given analysis period. }\end{array}$ & $6.7 \%$ & {$[7,70,78,91,93,100,131,138]$} \\
\hline Deceleration & $\mathrm{m} \mathrm{s}^{-2}$ & $\begin{array}{l}\text { Intensity metric of any magnitude of } \\
\text { dec over given analysis period. }\end{array}$ & $4.2 \%$ & {$[7,47,70,78,100]$} \\
\hline $\begin{array}{l}\text { Acceleration } \\
\text { Density Index }\end{array}$ & $\begin{array}{l}\text { Avg Accl } \\
\text { Dec per } 10 \\
\text { m; } \mathrm{m} \mathrm{s}^{-}\end{array}$ & $\begin{array}{l}\text { Average acceleration performed per } 10 \\
\mathrm{~m} \text { of distance covered (Acceleration } \\
\text { Load/Distance) }\end{array}$ & $0.8 \%$ & [45] \\
\hline \multirow[t]{2}{*}{$\begin{array}{l}\text { Acceleration } \\
\text { Load }\end{array}$} & $\begin{array}{l}\text { Total Acc/ } \\
\text { Dec; } \mathrm{m} \mathrm{s}^{-2}\end{array}$ & $\begin{array}{l}\text { Sum of acceleration values across the } \\
\text { analysed period }\end{array}$ & $0.8 \%$ & {$[45]$} \\
\hline & $\mathrm{AU}$ & $\begin{array}{l}\text { Average absolute value of all acc/dec } \\
\text { data relative to a defined period. } \\
\text { Absolute value multiplied by defined } \\
\text { duration to convert to load metric }\end{array}$ & $0.8 \%$ & [135] \\
\hline $\begin{array}{l}\text { Average } \\
\text { Accel/Decel }\end{array}$ & $\left(\mathrm{m} \mathrm{s}^{-2}\right)$ & $\begin{array}{l}\text { Absolute acceleration/deceleration } \\
\text { values averaged across the specified } \\
\text { period }\end{array}$ & $9.2 \%$ & {$[6,7,9-11,45,58,61,81-83]$} \\
\hline \multirow[t]{4}{*}{ Time } & Seconds & Time in respective threshold band & $4.2 \%$ & {$[7,75,93,104,113]$} \\
\hline & $\%$ time & $\begin{array}{l}\text { Time spent as a percentage in } \\
\text { respective threshold band }\end{array}$ & $0.8 \%$ & [84] \\
\hline & $\begin{array}{l}\% \text { time per } \\
\text { minute }\end{array}$ & $\begin{array}{l}\text { Percentage time spent in respective } \\
\text { threshold band with respect to activity } \\
\text { time and threshold }\end{array}$ & $1.7 \%$ & {$[85,86]$} \\
\hline & $\begin{array}{l}\text { Minutes per } \\
\text { count }\end{array}$ & $\begin{array}{l}\text { Efforts in respective threshold band with } \\
\text { respect to activity time }\end{array}$ & $2.5 \%$ & [132-134] \\
\hline $\begin{array}{l}\text { Ratio of Dec: } \\
\text { Acc }\end{array}$ & $\begin{array}{l}\text { Ratio } \\
\text { Dec:Acc }\end{array}$ & $\begin{array}{l}\text { Duration of Dec (High) and Dec (Mod) } \\
\text { divided by total Acc time (High }+ \text { Mod) } \\
\text { in each period. }\end{array}$ & $0.8 \%$ & [104] \\
\hline
\end{tabular}

count threshold which may have practical implications for the practitioner and researcher [7]. Moreover, at the applied level, it is not uncommon to group athlete positional data together to gain an understanding for training and match loads [7]. If the combined positional average data has existing variability at the individual athlete level, this may then extend into variation seen in the group average [7]. This review anticipates the implementation of count, distance, and other threshold-based metrics in the reporting of acceleration load will continue in future team sport research. However, it is important that researchers and practitioners understand the respective limitations outlined in these metrics before choosing to incorporate them in athlete load monitoring workflows.

\section{Choice of Athlete Tracking System}

Whilst this review sought to include all forms of athletetracking technology that outlined acceleration or deceleration loads, it is overwhelmingly clear that GPS/GNSS remains the most abundant and popular tracking 
technology within team sport research. From the results of this review, 113 out of the possible 124 studies (91\%) implemented GPS or GNSS devices to track athlete locomotion. This is not surprising given these devices were largely introduced in $\sim 2004$ and as such have seen continued developments in their technology as well as their commercial availability to practitioners [2, 152]. The continued progressions in the capabilities of GPS/ GNSS devices, with regard to improvements in device sample rates, along with the allowance to wear these devices in most major competitions, have seen these tools become commonplace in the load monitoring of team sport athletes $[1,8,22]$. The widespread acceptance of these devices (at the applied level) can be attributed to the many benefits GPS/GNSS provide the practitioner. These tools provide objective and unobtrusive data collection from the athlete on their external loads in real time, which can be further analysed to develop training programs and activity profiles aimed at preparation for competition [3] . This is aided by the nature of outdoor team sports, particularly those conducted at stadia/practice facilities with no overhanging structures or surrounding infrastructure that may occlude or partially occlude the sky. With minimal occlusion, GPS/GNSS satellite signal connection is maintained and therefore allows for improved athlete-tracking data quality. In turn, there is no additional GPS/GNSS device setup required by the practitioner, which enhances the practicality of tracking athlete movement during training and competition [2].

\section{Distribution of GPS/GNSS Devices}

The results of this review saw the utilisation of 21 different GPS/GNSS device models from seven manufacturers in the outlining of acceleration and deceleration loads from the study cohort. Whilst the inclusion criteria of this review only included GPS/GNSS devices with sample rates at or above $5 \mathrm{~Hz}$, there was a representation of both $5-\mathrm{Hz}$ and $10-\mathrm{Hz}$ devices from manufacturers. It is generally accepted that the use of 5-Hz GPS technology is disadvantageous compared to the greater capacities of $10-\mathrm{Hz}$ devices, particularly at high-intensity acceleration and decelerations $[3,21]$. In the context of the calculation of acceleration and deceleration however, the number of manufacturers and GPS/GNSS devices used, regardless of sample rate, raises concern surrounding data consistency in reporting and methodology. The concern surrounding the number of GPS/GNSS devices used stems from the known differences that exist in the data filtering methods and minimum effort durations utilised between manufacturers in the calculation of acceleration $[26,27]$. This review is not suggesting that the number of devices or manufacturers of wearable technologies is an issue, but rather the issue lies in the differences in their methods to calculate acceleration. With the number of the devices and manufacturers seen in this review, it is anticipated that at least on the manufacturer level, differences exist in acceleration processing [26]. The difference in acceleration processing may then extend between device models, device firmware and between the proprietary software processing acceleration data [26]. Ultimately, variation between tracking devices could have the potential to create technology-driven rather than athlete-driven differences in acceleration/deceleration loads [26].

\section{Local Positioning Systems in Team Sport Research Background}

Historically, it has been difficult for indoor-based team sports to capture their external athlete loads during training and competition [153, 154]. Despite the continued growth of GPS/GNSS technology for outdoor team sports, the obvious limitation of enclosed stadium infrastructure means that GPS/GNSS signals cannot accurately penetrate and track indoor sports [131]. As a consequence, there has been limited technology available to indoor team sport practitioners to adequately capture external athlete loads with sports such as Basketball, Netball, Handball and Futsal relying upon optical systems to track athlete locomotion [153]. The introduction of local positioning systems (LPS) or local positioning measurement (LPM) however has seen sustained development since the inception of Radio Frequency Identification (RFID) systems [154-158]. Previously suggested to be the most abundant LPS within applied sport science, RFID systems operate by measuring the distance between anchor nodes at known locations around the field of play with athletes wearing the mobile nodes [154, 159]. Acceptable levels of accuracy exist during locomotion for RFID systems for measuring distance (mean error 1.26-3.87\%) and for average and maximal velocity (3.54\% and $13.15 \%$, respectively) $[155,158,159]$. However, RFID systems can be limited by incidents of signal instability and interference $[159,160]$. The developments of LPS systems that operate via UltraWideband (UWB) technology have been suggested to overcome the limitations of signal instability in RFID systems $[153,159]$. The enhanced technology seen in UWB systems allows for greater precision, with signals that are capable of penetrating many structural materials $[153,160]$. The existing literature evaluating UWB-based LPS systems is limited but two UWB systems (WIMU Pro \& Catapult ClearSky T6) are a valid means to assess the positioning of indoor court athletes $[153,154,159$, 161]. Operationally, LPS devices operate through shortrange communication wave generators that are in contact with receivers [153]. Local positioning system 
receivers are fixed to various points around the stadium to maximise full court coverage of the technology [153].

\section{Interaction of LPS Systems with Outdoor Team Sport Tracking}

Whilst LPS-based studies represented a small contribution to the overall review, it is important to discuss the interaction of UWB and radiofrequency technology with outdoor team sport tracking. Given the development of UWB technology, the recent validation studies and the requirement for tracking system technology for indoorbased team sport athletes, it is anticipated that the use of LPS to measure acceleration load will continue [153]. The prevalence of UWB LPS can be seen in applied sport science with the increasing utilisation of LPS in outdoor-team sport stadia [2, 26]. With the exception of the use of optical tracking in soccer, many outdoor team sports have historically tracked external athlete loads in training and competition using GPS/GNSS technology. However, during outdoor-team sport competition in stadiums with obtrusive infrastructure, there have been instances of disruptions in signal quality. The disruptions may occur from overhanging stadium structures which disrupt the signal line of sight with satellites. To alleviate signal quality concerns, UWB LPS technology has been erected within outdoor stadia to remove the signal interference seen in GPS/GNSS data [26]. It may be that with further UWB LPS development, these systems will be preferred over the traditional GPS/GNSS devices during competition within large stadiums. Regardless, the development of LPS for indoor-based team sports is important for the analysis of the acceleration load of these athletes. However, it must be presented to practitioners that LPS technology is not without limitation. To utilise LPS, stadia must be appropriately fitted with the correct infrastructure before tracking can take place. This cost is expensive and may be problematic with venues that facilitate sporting and entertainment events [159]. Similarly, to utilise this technology for away fixtures, the LPS infrastructure must be installed in the away venue which requires compatible technology to be of use [26].

\section{Alternative Acceleration Metrics}

The results of this review identified metrics outside of the traditional threshold-based variables for quantifying acceleration. This review identified that team sport researchers have implemented the absolute acceleration variable to quantify acceleration load. Specifically, $9 \%$ of the studies included in this review presented the absolute acceleration metric, with the majority of the studies originating from the same research group $[6,7,10,11$, $45,58,61,81-83,135]$. Absolute acceleration combines the absolute value of all acceleration data (regardless of the magnitude) and is averaged over the given time period (e.g., drill or match) [9]. The use of absolute acceleration avoids the issue of dichotomising a continuous variable into acceleration thresholds, as all acceleration events are included and are not subject to device reliability issues that are seen with thresholdbased metrics [162]. For athlete load monitoring, incorporating all acceleration events may be beneficial as all acceleration events carry a physiological and mechanical cost that needs to be accounted for [7]. At the research level, the reliability of this method was also found to be good to moderate in both $5-\mathrm{Hz}(\mathrm{CV} 5.7 \%)$ and $10-\mathrm{Hz}$ (CV $1.2 \%$ ) devices [7] when compared to VICON [163], rendering the variable suitable for team sport monitoring.

Since the introduction of the absolute acceleration metric, there have been derivative metrics of this variable introduced into research [9]. Firstly, acceleration density index (ADI) (avg Acc/Dec per $10 \mathrm{~m} ; \mathrm{m} \mathrm{s}^{-2}$ ) incorporates the absolute acceleration metric, but is calculated as absolute acceleration performed per $10 \mathrm{~m}$ of distance covered [45]. In essence, ADI is analysing acceleration load relative to distance [45]. At the applied level, ADI may provide benefit to court-based sports such as Netball or Basketball where athletes may not accumulate high acceleration load relative to total activity time (subject to rest), but accumulate substantial acceleration load during locomotion (e.g., goal shooters/goal keepers in netball or centres/power forwards in basketball) [45]. Secondly, load measures that derive from absolute acceleration were evident in this review. Acceleration total load (total Acc/Dec; $\mathrm{m} \mathrm{s}^{-2}$ ) summates the accumulation of all acceleration events over an analysed time period [45]. For athlete monitoring, total acceleration load can be implemented as a standalone metric or it can be used as a supplementary variable which summates the information in threshold-based acceleration metrics [45]. Similarly, acceleration load (arbitrary units; AU) featured in this review, was quantified by calculating absolute acceleration over the analysed period before multiplying the value by duration to convert to load (AU) [135]. With the growth of the absolute acceleration metric and the subsequent derivate metrics, the implementation of these variables both practically and in research is likely to continue.

\section{Limitations of Included Studies}

With the increasing prevalence of athlete-tracking technologies in applied sport science, there has been a requirement for standardised processes when collecting and reporting upon athlete datasets $[1,8]$. The basis for a standardised collecting and reporting process is to ensure greater consistency and transparency when reporting activity profiles or external athlete load in research. In keeping with the recommendations outlined by 
Malone et al. [1], this review attempted to extract values surrounding the quality of satellite data when tracking athletes over the analysed period. Specifically, this review analysed the HDOP and the number of satellites connected to devices during the analysed activity. The horizontal dilution of precision provides a value of the accuracy of the GPS/GNSS horizontal positional signal as determined by the geographical positioning of the satellites [164]. Generally, when satellites are spread out, HDOP is low which enhances data quality [25, 165]. To rank HDOP quality, a scale of $1-50$ is implemented [1, 25]. Any HDOP value below 1 is considered optimal for HDOP readings with at least four to six satellites being required to capture human movement $[1,25]$. Despite the importance of these metrics pertaining to the data quality of each individual study, this review was limited by a lack of information surrounding HDOP and the number of satellite details. For HDOP, only $24 \%$ of the eligible GPS/GNSS studies specified a HDOP value for their respective study. Similarly, only $27 \%$ of studies outlined the mean number of satellites connected to the tracking device during the analysed periods. Consequently, it is difficult to make inferences regarding the studies included in this review without sufficient information regarding their data quality. Moreover, at an applied level, it is then difficult for practitioners to make judgements regarding activity profiles. The authors do acknowledge however that whilst all GPS/GNSS devices are capable of collecting HDOP and information on the number of satellites, the access to this information may be limited by device manufacturers, which in turn may not have been made available to researchers [1]. However, with the availability of GNSS planning tools, researchers and practitioners are still be able to obtain information relating to the availability of satellites and HDOP measures during data collection. Planning tools should be consulted to document the satellite activity during the data collection to supplement the satellite information from GPS/GNSS devices. Future research should endeavour to specify HDOP and satellite information where possible to allow researchers and practitioners a wholistic opportunity to evaluate research data quality.

Despite the potential differences that may exist between athlete-tracking device hardware and specifications (e.g., device sample rate), the way in which acceleration events are calculated can result in substantial variation in acceleration load $[1,26,27]$. It is accepted that different athlete-tracking devices and manufacturers process acceleration events in different ways. Firstly, acceleration is not directly measured by the tracking device. As a result, acceleration is calculated as a derivative measure of velocity (for GNSS) [24, 166]. Secondly, there is a sweeping issue with the reporting of athlete-tracking data in which there is no consensus method to process acceleration events. These two points coupled with the increasing amount of wearable tracking devices and manufacturers available to practitioners has potentially created technology-driven variations in acceleration load between devices [1,26]. Variations include the filtering of velocity and/or acceleration data by device manufacturers and also the selection of minimum effort durations (MED) for acceleration events [8, 27].

The filtering of athlete tracking data can directly influence acceleration load, regardless of the magnitude or metric used to quantify the event $[1,8,26,27]$. The purpose of filtering extends to maintaining data quality, removing poor signals and to decreasing the noise content of the signal [23, 166-169]. In human movement, there are many different types of filters which have been introduced to process athlete data [23]. Firstly, bandpass filters help to convert raw data from the spatial to the time domain via the use of a Fourier Fast Transform (FFT) $[23,166,170]$. The use of low pass filters allows for low-frequency signals to pass whilst minimising the high-frequency noise, whereas digital filtering processes the frequency spectrum of the noise and the signal [23]. In LPS, common filtering methods include, but are not limited to, Kalman and Butterworth filters, whilst GPS/ GNSS devices can also utilise Butterworth as well as moving average, moving median, median or exponential filters $[1,23,49,63,131,157,158,166]$. However, the process by which manufacturers select their filtering process is arbitrary and can vary from manufacturer to manufacturer [1]. In research and for applied sport science practitioners, this is problematic as there are many different manufacturers and devices commercially available. As such, there are many different types of filters that can be modified, potentially altering the magnitude of an acceleration event [26]. For example, manufacturers may elect to filter the velocity trace using a determined filter and then calculate acceleration from the velocity trace. Manufacturers may also filter the velocity trace and then filter the calculation of acceleration using a predefined filter. Therefore, consistency in the reporting of filtering methods is required when processing athlete acceleration data. In this review, only $13 \%$ of studies detailed the filter used when processing athlete movement data. This detail includes proprietary filters as defined by the manufacturers and custom filters applied by researchers. The lack of information surrounding the filtering processes in these studies then raises questions as to any identified differences between the research. Are these differences driven by the discrepancies between athlete-based external outputs or are they derived from technology-driven influences from the use of different data processing methods [26]? However, in posing this question, the researchers do acknowledge that in similar 
regard to satellite and HDOP information, the filtering process used in the calculation of acceleration via the manufacturer's proprietary software may not be made available.

With the lack of critical information on filtering and signal quality, the authors of this review were limited in the ability to make judgements and comparisons on acceleration. It is difficult to assess external athlete load without knowing how the acceleration data were processed, given the known influence these processes have on athlete external loads $[1,8,26]$. Therefore, it is important that future research outlines the filtering processes used in the calculation of acceleration to ensure appropriate comparisons between tracking technology and external athlete load. However, if future research begins to improve the reporting process on filtering in the calculation of acceleration, there may still be issues surrounding the comparability of acceleration load between athlete-tracking technologies and manufacturers. There may still be technology-driven discrepancies between activity profiles and validity and reliability studies of wearable technology [26]. Following the summations of Thornton et al. [26], this review contends that future research should be centred towards a consistent method to process acceleration. Despite the majority of the discussion surrounding GPS/GNSS technology, it is anticipated that these same difficulties would occur with local positioning systems and optical systems [26].

The minimum effort duration (MED) is a qualifying criterion in which acceleration events need to be sustained for a specific time frame for the effort to be acknowledged as an event $[8,27]$. For instance, if a MED of $0.5 \mathrm{~s}$ was chosen, the athlete would need to maintain the acceleration for at least $0.5 \mathrm{~s}$ for it to qualify as an event [27]. However, the selection of the MED is problematic as the MED and any accompanying velocity threshold (where applicable) is generally arbitrary. The arbitrary selection of the MED may be due to many factors including the inconsistency in the selection of the MEDs within previous team sport research and the use of different tracking devices and manufacturers. Currently, there is no consensus or consistent MED outlined in athlete-tracking-based studies and as such, there has been a wide variety of different MEDs presented to calculate external athlete acceleration load $[8,27]$. In this review, there were six different MEDs selected, ranging from $0.2 \mathrm{~s}$ to $2 \mathrm{~s}$, with the $0.5 \mathrm{~s}$ threshold being the most frequent. Moreover, approximately $68 \%$ of the included studies in this review did not specify their MED for acceleration or deceleration events.

The variation in MEDs between studies is in itself problematic, as the calculation interval directly influences the magnitude of an acceleration $[8,27]$. In the Harper et al. [8] review, the study made the point that small fluctuations between MED intervals (i.e., $0.1 \mathrm{~s}$ ) can result in differences in the number of high-intensity acceleration efforts. The suggestion from Harper et al. [8] is based on the original research from Varley et al. [27], which quantified the impact of differing MEDs (from $0.1 \mathrm{~s}$ to $1.0 \mathrm{~s}(0.1 \mathrm{~s}$ increments)) upon acceleration counts. In this research, the authors concluded that during an elite Dutch soccer match, there was an exponential decline in the number of observed acceleration efforts as the MED increased, across all filtering methods [27]. In essence, this finding confirmed that the selection of a lower MED of 0.1-0.3 s (GNSS) is more appropriate for capturing short and discrete acceleration events [8]. However, MEDs of 0.1-0.3 s (GNSS) in length are also more susceptible to any error in measurement that may be a result of numerous repeat accelerations that occur too closely together [8]. Conversely, a MED of longer duration $(>0.5 \mathrm{~s})$ may have a smoothing effect on the acceleration datapoints for GNSS-based technology, which in turn may dampen the magnitude of higher acceleration events or may underestimate the number of efforts [27]. It should be stressed that this research is GNSS based and may have different implications for LPS/LPM technology.

There is no one "perfect" MED for the calculation of athlete acceleration [27]. However, it is prudent for practitioners to realise the implications of the selection of a MED and how this may be compared with similar team sport activity profiles [27]. It is also recognised by the researchers that the choice of a MED may be dictated by the tracking device model/manufacturer. Similar to the choice of filtering applied to acceleration data, practitioners may be limited to the MED specifications outlined by the manufacturer, whilst other manufacturers may allow complete customisation of the process. Regardless of the situation, differences in MED settings can still lead to differences in acceleration load between research studies.

To alleviate the potential differences in load as a result of different MED settings, previous research has highlighted the use of a threshold inclusion criteria [8, 27]. The inclusion criteria suggested that a qualifying threshold standard for an acceleration effort could be implemented alongside a MED. For example, the acceleration must eclipse $1 \mathrm{~m} \mathrm{~s}^{-2}$ for the effort to be counted. Moreover, to establish an acceleration endpoint for an effort, this could be implemented when acceleration falls below $0 \mathrm{~m} \mathrm{~s}^{-2}[8,27]$. The issue of varied MEDs in research however still exists with this method. With inconsistencies seen between MEDs in this review, future research may then look to identify appropriate MEDs with respect to each team sport. The presence of MEDs with respect to each team sport would then create a more consistent approach to acceleration/deceleration reporting. 


\section{Future Research}

To improve future research, studies should attempt to improve the consistency in the processing and reporting of team sport acceleration and deceleration loads. Specifically, future research should be guided by the following recommendations:

- Report the HDOP and number of satellites in connection with devices during data collection (satellite-based technology only).

- Report the acceleration processing method, including any filtering methods (if known and applicable) and the minimum effort duration.

- Utilise GNSS planning tools (where applicable) to evaluate the performance of their respective wearable tracking system relative to the available satellites (satellite-based technology only).

- Move towards the determination of a common acceleration filter that can be used practically and within research that may be sport specific.

When reporting acceleration load from tracking devices, it is important that future studies attempt to outline the HDOP and the average number of satellites in connection with the devices during analysis. Satellite information can be used by researchers and practitioners as an indication of the signal quality from these devices and can aid in the evaluation of the quality of the acceleration/deceleration datasets. In terms of acceleration metrics, future research should also endeavour to outline the acceleration filtering used to process the acceleration data (if known and applicable) and the MED to quantify any threshold-based metrics.

Future research should attempt to introduce a common acceleration filtering technique for the processing of external athlete acceleration and deceleration loads. A common filtering technique that is sport specific may be appropriate. However, the amount of tracking devices, manufacturers and systems seen in this review highlights the importance of having a consistent process to handle and process acceleration data. Without a consistent process and with the known influence filtering methods have upon acceleration/deceleration data, future research will continue to question whether differences in acceleration/deceleration loads are athlete or technology driven [26].

\section{Conclusions}

Acceleration metrics are important components of the external load monitoring process of team sport athletes. The ability to quantify acceleration events allows practitioners to understand the energetic (acceleration-focused) and eccentric load placed upon the athlete during training and competition [7]. With athlete acceleration information, acceleration-specific loads can be accounted for in the athlete preparatory process.

Acceleration events in team sport research have been predominately quantified via the use of effort counts, including counts related to time. Other "traditional" metrics in terms of acceleration being quantified via distance remains a relevant selection, as does average intensity by practitioners.

Global Positioning Systems and now GNSS are the most common tracking systems utilised in the quantification of acceleration in the team sport athlete. However, despite the widespread use of GPS/GNSS technology in tracking athlete locomotion, there is a lack of information surrounding the signal quality via the HDOP and number of satellite metrics. Future research should aim to outline HDOP and the number of satellites where possible, to allow researchers to evaluate the quality of the athlete tracking data.

The calculation of acceleration in the athlete-tracking device is influenced by MEDs and the specification of data filtering processes. Despite the influence and variation of data filtering and MEDs between tracking device manufacturers, these metrics have not been consistently published in research. This review concludes that even if future studies outlined the acceleration data filtering process, the anticipated variation between tracking manufacturers and devices may highlight technology-driven influences in acceleration/deceleration loads. Therefore, a consistent and potentially sport-specific acceleration filtering process and reporting structure needs to be developed and introduced within applied team sport research.

\section{Abbreviations \\ AU: Arbitrary units; Acc: Acceleration; ADI: Acceleration density index; CV: Coefficient of variation; Dec: Deceleration; FFT: Fast Fourier Transform; GNSS: Global Navigation Satellite System; GPS: Global Positioning System; HDOP: Horizontal Dilution of Precision; LPM: Local Positioning Measurement; LPS: Local Positioning System; MED: Minimum effort duration; PRIS MA: Preferred items for Systematic Reviews and Meta-Analyses; RFID: Radio Frequency Identification systems; UWB: Ultra-wideband}

\section{Acknowledgements \\ Not applicable. \\ Code Availability \\ Not applicable. \\ Authors' Contributions \\ $\mathrm{RD}$ wrote the manuscript and performed the systematic review search. All authors contributed to conception of the systematic review. RD and GD devised the search parameters for the systematic review. All authors contributed to the interpretation of the results. All authors reviewed the manuscript. All authors read and approved the final manuscript.}

\section{Funding}

No funding was received for the preparation of this article.

Availability of Data and Materials

Not applicable. 


\section{Declarations}

Ethics Approval and Consent to Participate

Not applicable.

\section{Consent for Publication}

Not applicable.

\section{Competing Interests}

The authors, Robert Delves, Robert Aughey, Kevin Ball, and Grant Duthie, declare that they have no competing interests.

\section{Author details}

${ }^{1}$ Institute for Health \& Sport, Victoria University, Melbourne, VIC 3011, Australia. ${ }^{2}$ School of Behavioural and Health Sciences, Australian Catholic University, Strathfield, NSW, Australia.

\section{Received: 10 November 2020 Accepted: 30 May 2021}

Published online: 30 June 2021

\section{References}

1. Malone JJ, Lovell R, Varley MC, Coutts AJ. Unpacking the black box: applications and considerations for using GPS devices in sport. Int J Sports Physiol Perform. 2017;12:S2-18-26.

2. Aughey RJ. Applications of GPS technologies to field sports. Int I Sports Physiol Perform. 2011;6(3):295-310. https://doi.org/10.1123/ijspp.6.3.295.

3. Scott MTU, Scott TJ, Kelly VG. The validity and reliability of Global Positioning Systems in team sport: a brief review. J Strength Cond Res. 2016;30(5):1470-90. https://doi.org/10.1519/JSC.0000000000001221.

4. Osgnach C, Poser S, Bernardini R, Rinaldo R, di Prampero PE. Energy cost and metabolic power in elite soccer: a new match analysis approach. Med Sci Sports Exerc. 2010;42(1):170-8. https://doi.org/10.1249/MSS.0b013e3181a e5cfd.

5. Reilly T, Bangsbo J, Franks A. Anthropometric and physiological predispositions for elite soccer. J Sports Sci. 2000;18(9):669-83. https://doi. org/10.1080/02640410050120050.

6. Delaney JA, Thornton HR, Rowell AE, Dascombe BJ, Aughey RJ, Duthie GM Modelling the decrement in running intensity within professional soccer players. Sci Med Football. 2018;2(2):86-92.

7. Delaney JA, Cummins CJ, Thornton HR, Duthie GM. Importance, reliability, and usefulness of acceleration measures in team sports. J Strength Cond Res. 2018:32(12):3485-93. https://doi.org/10.1519/JSC.0000000000001849.

8. Harper DJ, Carling C, Kiely J. High-intensity acceleration and deceleration demands in elite team sports competitive match play: a systematic review and meta-analysis of observational studies. Sports Med. 2019;49(12):1923-47.

9. Delaney JA, Duthie GM, Thornton HR, Scott TJ, Gay D, Dascombe BJ. Acceleration-based running intensities of professional rugby league match play. Int J Sports Physiol Perform. 2016;11(6):802-9.

10. Delaney JA, Thornton HR, Burgess DJ, Dascombe BJ, Duthie GM. Durationspecific running intensities of Australian Football match-play. J Sci Med Sport. 2017;20(7):689-94. https://doi.org/10.1016/j.jsams.2016.11.009.

11. Delaney JA, Thornton HR, Pryor JF, Stewart AM, Dascombe BJ, Duthie GM. Peak running intensity of international rugby: implications for training prescription. Int J Sports Physiol Perform. 2017;12(8):1039-45. https://doi. org/10.1123/ijspp.2016-0469.

12. Howe ST, Aughey RJ, Hopkins WG, Cavanagh BP, Stewart AM. Sensitivity, reliability and construct validity of GPS and accelerometers for quantifying peak periods of rugby competition. Plos One. 2020;15(7):1-23.

13. Wellman AD, Coad SC, Goulet GC, McLellan CP. Quantification of competitive game demands of NCAA division I college football players using Global Positioning Systems. J Strength Cond Res. 2016;30(1):11-9. https://doi.org/10.1519/JSC.0000000000001206.

14. Gastin PB, Hunkin SL, Fahrner B, Robertson S. Deceleration, acceleration, and impacts are strong contributors to muscle damage in professional Australian Football. J Strength Cond Res. 2019;33(12):3374-83.

15. Young WB, Hepner J, Robbins DW. Movement demands in Australian Rules Football as indicators of muscle damage. J Strength Cond Res. 2012;26(2): 492-6.

16. Russell M, Sparkes W, Northeast J, Cook CJ, Bracken RM, Kilduff LP. Relationships between match activities and peak power output and
Creatine Kinase responses to professional reserve team soccer match-play. Hum Mov Sci. 2016;45:96-101.

17. de Hoyo M, Cohen DD, Sañudo B, Carrasco L, Álvarez-Mesa A, del Ojo JJ, et al. Influence of football match time-motion parameters on recovery time course of muscle damage and jump ability. J Sports Sci. 2016;34(14):136370. https://doi.org/10.1080/02640414.2016.1150603.

18. Howatson G, Milak A. Exercise-induced muscle damage following a bout of sport specific repeated sprints. J Strength Cond Res. 2009;23(8):2419-24.

19. Thompson D, Nicholas CW, Williams C. Muscular soreness following prolonged intermittent high-intensity shuttle running. J Sports Sci. 1999; 17(5):387-95. https://doi.org/10.1080/026404199365902.

20. Nedelec M, McCall A, Carling C, Legall F, Berthoin S, Dupont G. The influence of soccer playing actions on the recovery kinetics after a soccer match. J Strength Cond Res. 2014;28(6):1517-23. https://doi.org/10.1519/JSC. 0000000000000293.

21. Cummins C, Orr R, O'Connor H, West C. Global Positioning Systems (GPS) and microtechnology sensors in team sports: a systematic review. Sports Med. 2013;43(10):1025-42. https://doi.org/10.1007/s40279-013-0069-2.

22. Varley M, Fairweather I, Aughey R. Validity and reliability of GPS for measuring instantaneous velocity during acceleration, deceleration, and constant motion. J Sports Sci. 2012;30(2):121-7. https://doi.org/10.1080/0264 0414.2011.627941.

23. Sweeting AJ, Cormack SJ, Morgan S, Aughey RJ. When is a sprint a sprint? A review of the analysis of team-sport athlete activity profile. Front Physiol. 2017:8:432.

24. Akenhead R, French D, Thompson KG, Hayes PR. The acceleration dependent validity and reliability of $10 \mathrm{~Hz}$ GPS. J Sci Med Sport. 2014;17(5): 562-6.

25. Witte TH, Wilson AM. Accuracy of non-differential GPS for the determination of speed over ground. J Biomech. 2004;37(12):1891-8.

26. Thornton HR, Nelson AR, Delaney JA, Serpiello FR, Duthie GM. Interunit reliability and effect of data-processing methods of Global Positioning Systems. Int J Sports Physiol Perform. 2019;14(4):432-8.

27. Varley MC, Jaspers A, Helsen WF, Malone JJ. Methodological considerations when quantifying high-intensity efforts in team sport using Global Positioning System technology. Int J Sports Physiol Perform. 2017;12(8): 1059-68. https://doi.org/10.1123/ijspp.2016-0534.

28. Whitehead S, Till K, Weaving D, Jones B. The Use of microtechnology to quantify the peak match demands of the football codes: a systematic review. Sports Med. 2018;48(11):2549-75. https://doi.org/10.1007/s40279-01 8-0965-6.

29. Taylor JB, Wright AA, Dischiavi SL, Townsend MA, Marmon AR. Activity demands during multi-directional team sports: a systematic review. Sports Med. 2017;47(12):2533-51.

30. Hausler J, Halaki M, Orr R. Application of Global Positioning System and microsensor technology in competitive rugby league match-play: a systematic review and meta-analysis. Sports Med. 2016;46(4):559-88.

31. Moher D, Liberati A, Tetzlaff J, Altman DG. Preferred reporting items for systematic reviews and meta-analyses: the PRISMA statement. BMJ. 2009;339(7716):332.

32. Akenhead R, Harley JA, Tweddle SP. Examining the external training load of an English Premier League football team with special reference to acceleration. J Strength Cond Res. 2016;30(9):2424-32. https://doi.org/10.151 9/JSC.0000000000001343.

33. Akenhead R, Hayes PR, Thompson KG, French D. Diminutions of acceleration and deceleration output during professional football match play. J Sci Med Sport. 2013;16(6):556-61. https://doi.org/10.1016/j.jsams.2012.12.005.

34. Akiyama K, Sasaki T, Mashiko M. Elite male lacrosse players' match activity profile. Journal of sports science \& medicine. 2019;18(2):290-4.

35. Altavilla G, Riela L, Di Tore AP, Raiola G. The physical effort required from professional football players in different playing positions. J Phys Educ Sport. 2017;17(3):2007-12.

36. Aughey RJ. Australian Football player work rate: evidence of fatigue and pacing? Int J Sports Physiol Perform. 2010;5(3):394-405. https://doi.org/1 0.1123/ijspp.5.3.394

37. Aughey RJ. Increased high-intensity activity in elite Australian Football finals matches. Int J Sports Physiol Perform. 2011;6(3):367-79.

38. Aughey RJ. Widening margin in activity profile between elite and sub-elite Australian Football: a case study. J Sci Med Sport. 2013;16(4):382-6. https:// doi.org/10.1016/j.jsams.2012.10.003.

39. Aughey RJ, Goodman CA, McKenna MJ. Greater chance of high core temperatures with modified pacing strategy during team sport in the heat. 
J Sci Med Sport. 2014;17(1):113-8. https://doi.org/10.1016/j.jsams.2013.02 013.

40. Bauer A, Young W, Fahrner B, Harvey J. GPS variables most related to match performance in an elite Australian Football team. Int J Perform Anal Sport. 2015;1:187.

41. Bayliff GE, Jacobson BH, Moghaddam M, Estrada C. Global Positioning System monitoring of selected physical demands of NCAA division I football players during games. J Strength Cond Res. 2019;33(5):1185-91 . https://doi.org/10.1519/JSC.0000000000003137.

42. Blair MR, Body SF, Croft HG. Relationship between physical metrics and game success with elite rugby sevens players. Int J Perform Anal Sport. 2017;17(4):418-28. https://doi.org/10.1080/24748668.2017.1348060

43. Bowen L, Gross AS, Gimpel M, Bruce-Low S, Li F-X. Spikes in acute:chronic workload ratio (ACWR) associated with a 5-7 times greater injury rate in English Premier League football players: a comprehensive 3-year study. Br J Sports Med. 2019;54(12):731-8.

44. Bradley PS, Di Mascio M, Peart D, Olsen P, Sheldon B. High-intensity activity profiles of elite soccer players at different performance levels. J Strength Cond Res. 2010;24(9):2343-51. https://doi.org/10.1519/JSC.0b013e3181aeb1b3.

45. Brooks ER, Benson AC, Fox AS, Bruce LM. Physical movement demands of elite-level netball match-play as measured by an indoor positioning system. J Sports Sci. 2020;38(13):1-8.

46. Campos-Vázquez MÁ, Castellano J, Toscano-Bendala FJ, Owen A. Comparison of the physical and physiological demands of friendly matches and different types of preseason training sessions in professional soccer players. / Comparación de las demandas físicas y fisiológicas entre partidos amistosos y diferentes sesiones de entrenamiento del periodo preparatorio en futbolistas profesionales. RICYDE Revista Int Ciencias del Deporte. 2019: 15(58):339-52.

47. Chesher SM, Netto KJ, Appleby BB, Jacques A, Wild CY. Deceleration characteristics of elite Australian male field hockey players during an Olympic tournament. J Sci Med Sport. 2019;22(5):611-5. https://doi.org/10.1 016/j.jsams.2018.11.019.

48. Clemente FM, Rabbani A, Conte D, Castillo D, Afonso J, Truman Clark CC, et al. Training/match external load ratios in professional soccer players: a full-season study. Int J Environ Res Public Health. 2019;16(17):3057.

49. Couderc A, Gabbett TJ, Piscione J, Robineau J, Peeters A, Igarza G, Thomas C, Hanon C, Lacome M Repeated high-intensity effort activity in international male rugby sevens. J Strength Cond Res. 2019, Publish Ahead of Print, doi: https://doi.org/10.1519/JSC.0000000000002986.

50. Coutts AJ, Kempton T, Sullivan C, Bilsborough J, Cordy J, Rampinini E. Metabolic power and energetic costs of professional Australian Football match-play. J Sci Med Sport. 2015;18(2):219-24. https://doi.org/10.1016/j.jsa ms.2014.02.003.

51. Cummins C, Cray A, Shorter K, Halaki M, Orr R. Energetic and metabolic power demands of national rugby league match-play. Int I Sports Med. 2016;37(7):552-8. https://doi.org/10.1055/s-0042-101795.

52. Cummins C, Welch M, Inkster B, Cupples B, Weaving D, Jones B, et al. Modelling the relationships between volume, intensity and injury-risk in professional rugby league players. J Sci Med Sport. 2019;22(6):653-60. https://doi.org/10.1016/j.jsams.2018.11.028.

53. Cummins CJ, Gray AJ, Shorter KA, Halaki M, Orr R. Energetic demands of interchange and full-match rugby league players. J Strength Cond Res. 2018;32(12):3447-55. https://doi.org/10.1519/JSC.0000000000001801.

54. Cunningham D, Shearer DA, Drawer S, Eager R, Taylor N, Cook C, et al. Movement demands of elite U20 international rugby union players. Plos one. 2016;11(4):e0153275. https://doi.org/10.1371/journal.pone.0153275.

55. Cunningham DJ, Shearer DA, Drawer S, Pollard B, Eager R, Taylor N, et al. Movement demands of elite under-20s and senior international rugby union players. PloS one. 2016;11(11):e0164990. https://doi.org/10.1371/ journal.pone.0164990.

56. Dalen T, Sandmæl S, Stevens TGA, Hjelde GH, Kjøsnes TN, Wisløff U. Differences in acceleration and high-intensity activities between small-sided games and peak periods of official matches in elite soccer players. J Strength Cond Res. 2019;35 (7):2018-24.

57. Dalen T, JØrgen I, Gertjan E, Havard HG, Ulrik W. Player load, acceleration, and deceleration during forty-five competitive matches of elite soccer. J Strength Cond Res. 2016;30(2):351-9.

58. Delves RIM, Bahnisch J, Ball K, Duthie GM. Quantifying mean peak running intensities in elite field hockey. J Strength Cond Res. 2019. Published Ahead of Print.
59. Dempsey GM, Gibson NV, Sykes D, Pryjmachuk BC, Turner AP. Match demands of senior and junior players during international rugby league. J Strength Cond Res. 2018;32(6):1678-84. https://doi.org/10.1519/JSC. 0000000000002028.

60. Dubois R, Paillard T, Lyons M, McGrath D, Maurelli O, Prioux J. Running and metabolic demands of elite rugby union assessed using traditional, metabolic power, and heart rate monitoring methods. Journal of Sports Science \& Medicine. 2017;16(1):84-92.

61. Duthie GM, Thomas EJ, Bahnisch J, Thornton HR, Ball K. Using small-sided games in field hockey: can they be used to reach match intensity? J Strength Cond Res. 2019. Published Ahead of Print.

62. Figueiredo P, Nassis GP, Brito J. Within-subject correlation between salivary $\operatorname{IgA}$ and measures of training load in elite football players. Int J Sports Physiol Perform. 2019;14(6):847-9. https://doi.org/10.1123/ijspp.2018-0455.

63. Furlan N, Waldron M, Shorter K, Gabbett TJ, Mitchell J, Fitzgerald E, et al. Running-intensity fluctuations in elite rugby sevens performance. Int J Sports Physiol Perform. 2015;10(6):802-7. https://doi.org/10.1123/ijspp.20140315

64. Gabbett TG. Sprinting patterns of national rugby league competition. J Strength Cond Res. 2012;26(1):121-30. https://doi.org/10.1519/JSC.0b013e31 821 e4c60.

65. Gabbett TJ. GPS analysis of elite women's field hockey training and competition. J Strength Cond Res. 2010;24(5):1321-4. https://doi.org/10.151 9/JSC.0b013e3181ceebbb.

66. Gabbett TJ. Influence of the opposing team on the physical demands of elite rugby league match play. Journal of strength and conditioning research. 2013;27(6):1629-35. https://doi.org/10.1519/JSC.0b013e318274f30e.

67. Gabbett TJ, Jenkins DG, Abernethy B. Influence of wrestling on the physiological and skill demands of small-sided games. J Strength Cond Res. 2012;26(1):113-20. https://doi.org/10.1519/JSC.0b013e31821d97f4.

68. Gabbett TJ, Ullah S. Relationship between running loads and soft-tissue injury in elite team sport athletes. J Strength Cond Res. 2012;26(4):953-60. https://doi.org/10.1519/JSC.0b013e3182302023.

69. Garvican LA, Hammond K, Varley MC, Gore CJ, Billaut F, Aughey RJ. Lower running performance and exacerbated fatigue in soccer played at $1600 \mathrm{~m}$ Int J Sports Physiol Perform. 2014;9(3):397-404. https://doi.org/10.1123/ ijspp.2012-0375.

70. Gaudino P, Alberti G, laia FM. Estimated metabolic and mechanical demands during different small-sided games in elite soccer players. Hum Mov Sci. 2014;36:123-33. https://doi.org/10.1016/j.humov.2014.05.006.

71. Gaudino P, laia FM, Strudwick AJ, Hawkins RD, Alberti G, Atkinson G, et al. Factors influencing perception of effort (session rating of perceived exertion) during elite soccer training. Int J Sports Physiol Perform. 2015;10(7):860-4.

72. Hauer R, Tessitore A, Hauer K, Tschan H. Activity profile of international female lacrosse players. J Strength Cond Re. 2019. Published Ahead of Print.

73. Higham DG, Pyne DB, Anson JM, Eddy A. Movement patterns in rugby sevens: Effects of tournament level, fatigue and substitute players. J Sci Med Sport. 2012;15(3):277-82. https://doi.org/10.1016/j.jsams.2011.11.256.

74. Higham DG, Pyne DB, Anson JM, Hopkins WG, Eddy A. Comparison of activity profiles and physiological demands between international rugby sevens matches and training. J Strength Cond Re. 2016;30(5):1287-94. https://doi.org/10.1097/JSC.0000000000000212.

75. Hoppe MW, Baumgart C, Slomka M, Polglaze T, Freiwald J. Variability of metabolic power data in elite soccer players during pre-season matches. $J$ Hum Kinetics. 2017:58(1):233-45.

76. Ihsan M, Yeo V, Tan F, Joseph R, Lee M, Aziz AR. Running demands and activity profile of the new four-quarter match format in men's field hockey. J Strength Cond Res. 2018;35 (2): 512-8.

77. Ingebrigtsen J, Dalen T, Hjelde GH, Drust B, Wisløff U. Acceleration and sprint profiles of a professional elite football team in match play. Eur J Sport Sci. 2015;15(2):101-10.

78. Jackson BM, Polglaze T, Dawson B, King T, Peeling P. Comparing Global Positioning System and Global Navigation Satellite System Measures of Team-Sport Movements. Int J Sports Physiol Perform. 2018;13(8):1005-10. https://doi.org/10.1123/ijspp.2017-0529.

79. Jaspers A, TO DB, Brink MS, Frencken WGP, Staes F, Davis JJ, et al. Relationships between the external and internal training load in professional soccer: what can we learn from machine learning? Int I Sports Physiol Perform. 2018;13(5):625-30. https://doi.org/10.1123/ijspp.2017-0299.

80. Jaspers A, Kuyvenhoven JP, Staes F, Frencken WGP, Helsen WF, Brink MS Examination of the external and internal load indicators' association with 
overuse injuries in professional soccer players. J Sci Med Sport. 2018;21(6): 579-85. https://doi.org/10.1016/j.jsams.2017.10.005.

81. Johnston RD, Devlin P, Wade JA, Duthie GM. There is little difference in the peak movement demands of professional and semi-professional rugby league competition. Front Physiol. 2019;10:1285. https://doi.org/10.3389/ fphys.2019.01285.

82. Johnston RD, Thornton HR, Wade JA, Devlin P, Duthie GM. The distribution of match activities relative to the maximal mean intensities in professional rugby league and Australian Football. J Strength Cond Res. 2020. Published Ahead of Print.

83. Johnston RD, Weaving D, Hulin BT, Till K, Jones B, Duthie G. Peak movement and collision demands of professional rugby league competition. J Sports Sci. 2019;37(18):2144-51.

84. Johnston RJ, Watsford ML, Austin DJ, Pine MJ, Spurrs RW. An examination of the relationship between movement demands and rating of perceived exertion in Australian Footballers. J Strength Cond Res. 2015;29(7):2026-33. https://doi.org/10.1519/JSC.0000000000000816.

85. Johnston RJ, Watsford ML, Austin DJ, Pine MJ, Spurrs RW. Movement demands and metabolic power comparisons between elite and subelite Australian footballers. J Strength Cond Res. 2015;29(10):2738-44. https://doi. org/10.1519/JSC.0000000000000936

86. Johnston RJ, Watsford ML, Austin DJ, Pine MJ, Spurrs RW. Movement profiles, match events and performance in Australian football. J Strength Cond Res. 2016;30(8):2129-37. https://doi.org/10.1519/JSC. 0000000000001333.

87. Jones MR, West DJ, Crewther BT, Cook CJ, Kilduff LP. Quantifying positional and temporal movement patterns in professional rugby union using global positioning system. Eur J Sport Sci. 2015;15(6):488-96. https://doi.org/10.1 080/17461391.2015.1010106.

88. Kempton T, Coutts AJ. Physical and technical demands of Rugby League $9 \mathrm{~s}$ tournament match play: a preliminary study. Int J Sports Physiol Perform. 2015;10(6):774-9.

89. Kempton T, Sirotic AC, Coutts AJ. A comparison of physical and technical performance profiles between successful and less-successful professional rugby league teams. Int J Sports Physiol Perform. 2017;12(4):520-6. https:// doi.org/10.1123/ijspp.2016-0003.

90. Kempton T, Sirotic AC, Rampinini E, Coutts AJ. Metabolic power demands of rugby league match play. Int J Sports Physiol Perform. 2015;10(1):23-8.

91. Lacome M, Piscione J, Hager J-P, Bourdin M. A new approach to quantifying physical demand in rugby union. J Sports Sci. 2014;32(3):290-300. https:// doi.org/10.1080/02640414.2013.823225.

92. Malone JJ, Jaspers A, Helsen W, Merks B, Frencken WGP, Brink MS. Seasonal training load and wellness monitoring in a professional soccer goalkeeper. Int J Sports Physiol Perform. 2018;13(5):672-5. https://doi.org/10.1123/ijspp.2017-0472.

93. Mara JK, Thompson KG, Pumpa KL. Physical and physiological characteristics of various-sided games in elite women's soccer. Int J Sports Physiol Perform. 2016;11(7):953-8. https://doi.org/10.1123/IJSPP.2015-0087.

94. Mara JK, Thompson KG, Pumpa KL, Ball NB. Periodization and physical performance in elite female soccer players. Int I Sports Physiol Perform. 2015;10(5):664-9. https://doi.org/10.1123/ijspp.2014-0345.

95. Marrier B, Le Meur Y, Leduc C, Piscione J, Lacome M, Igarza G, et al. Training periodization over an elite rugby sevens season: from theory to practice. Int J Sports Physiol Perform. 2019;14(1):113-21.

96. Martin-Garcia A, Castellano J, Diaz AG, Cos F, Casamichana D. Positional demands for various-sided games with goalkeepers according to the most demanding passages of match play in football. Biol Sport. 2019;36(2):17180. https://doi.org/10.5114/biolsport.2019.83507.

97. Martín-García A, Castellano J, Villanueva AM, Gómez-Díaz A, Cos F, Casamichana D. Physical demands of ball possession games in relation to the most demanding passages of a competitive match. J Sports Sci Med. 2020;19(1):1-9.

98. Martin-Garcia A, Gomez Diaz A, Bradley PS, Morera F, Casamichana D. Quantification of a professional football team's external load using a microcycle structure. J Strength Cond Res. 2018;32(12):3511-8. https://doi. org/10.1519/JSC.0000000000002816.

99. Modric T, Versic S, Sekulic D, Liposek S. Analysis of the association between running performance and game performance indicators in professional soccer players. Int J Environ Res Public Health. 2019;16(20):4032.

100. Montgomery PG, Maloney BD. Three-by-three basketball: inertial movement and physiological demands during elite games. Int J Sports Physiol Perform. 2018;13(9):1169-74. https://doi.org/10.1123/ijspp.2018-0031.
101. Morencos E, Casamichana D, Torres L, Romero-Moraleda B, Haro X, Rodas G. Kinematic demands of international competition in women's field hockey. I Demandes cinemàtiques de competició internacional en l'hoquei sobre herba femení. Apunts: Educació Física i Esports. 2019(137):56-70.

102. Morencos E, Romero-Moraleda B, Castagna C, Casamichana D. Positional comparisons in the impact of fatigue on movement patterns in hockey. Int J Sports Physiol Perform. 2018;13(9):1149-57. https://doi.org/10.1123/ijspp.2 017-0506.

103. Murray AM, Varley MC. Activity Profile of International Rugby Sevens: Effect of Score Line, Opponent, and Substitutes. Int J Sports Physiol Perform. 2015; 10(6):791-801. https://doi.org/10.1123/ijspp.2014-0004.

104. Newans T, Bellinger P, Dodd K, Minahan C. Modelling the acceleration and deceleration profile of elite-level soccer players. Int J Sports Med. 2019;40(5): 331-5. https://doi.org/10.1055/a-0853-7676.

105. Owen AL, Newton M, Shovlin A, Malone S. The use of small-sided games as an aerobic fitness assessment supplement within elite level professional soccer. J Hum Kinetics. 2020;71(1):243-53.

106. Owen SM, Venter RE, du Toit S, Kraak WJ. Acceleratory match-play demands of a Super Rugby team over a competitive season. J Sports Sci. 2015;33(19): 2061-9. https://doi.org/10.1080/02640414.2015.1028086.

107. Oxendale $\mathrm{CL}$, Twist $\mathrm{C}$, Daniels $\mathrm{M}$, Highton J. The relationship between match-play characteristics of elite rugby league and indirect markers of muscle damage. Int J Sports Physiol Perform. 2016;11(4):515-21. https://doi. org/10.1123/ijspp.2015-0406.

108. Palmer JA, Landers G, Buttfield A, Polglaze T. Physical demands of elite women's ultimate frisbee between halves and across matches in an international tournament. J Strength Cond Res. 2020;Publish Ahead of Print. https://doi.org/10.1519/JSC.0000000000003527.

109. Passos Ramos G, Datson N, Mahseredjian F, Lopes TR, Coimbra CC, Prado LS et al. Activity profile of training and matches in Brazilian Olympic female soccer team. Sci Med Football. 2019;3(3):231-7.

110. Passos Ramos G, Nakamura FY, Penna EM, Wilke CF, Pereira LA, Loturco I, et al. Activity profiles in U17, U20, and senior women's Brazilian national soccer teams during international competitions: are there meaningful differences? J Strength Cond Res. 2019;33(12):3414-22.

111. Passos Ramos G, Yuzo Nakamura F, Pereira LA, Brilhante Junior W, Mahseredjian F, Wilke CF, et al. Movement patterns of a U-20 national women's soccer team during competitive matches: influence of playing position and performance in the first half. Int J Sports Med. 2017:38(10):747-54

112. Peeters A, Carling C, Piscione J, Lacome M. In-Match Physical Performance fluctuations in international rugby sevens competition. J Sports Sci Med. 2019;18(3):419-26.

113. Polglaze T, Dawson B, Buttfield A, Peeling P. Metabolic power and energy expenditure in an international men's hockey tournament. Journal of Sports Sciences. 2018;36(2):140-8. https://doi.org/10.1080/02640414.2017.1287933.

114. Pollard BT, Turner AN, Eager R, Cunningham DJ, Cook CJ, Hogben P, et al. The ball in play demands of international rugby union. J Sci Med Sport. 2018;21(10):1090-4. https://doi.org/10.1016/j.jsams.2018.02.015.

115. Polley CS, Cormack SJ, Gabbett TJ, Polglaze T. Activity profile of high-level Australian lacrosse players. J Strength Cond Res. 2015;29(1):126-36. https:// doi.org/10.1519/JSC.0000000000000599.

116. Portillo J, González-Ravé JM, Juárez D, García JM, Suárez-Arrones L, Newton RU. Comparison of running characteristics and heart rate response of international and national female rugby sevens players during competitive matches. J Strength Cond Res. 2014;28(8):2281-9. https://doi.org/10.1519/JSC.0000000000000393.

117. Rennie MJ, Kelly SJ, Bush S, Spurrs RW, Austin DJ, Watsford ML. Phases of match-play in professional Australian Football: distribution of physical and technical performance. J Sports Sci. 2020;38(14):1-8.

118. Romero-Moraleda B, Morencos-Martínez E, Torres-Ronda L, Casamichana D. Analysis of congested schedule on competition external load in field hockey. / Análisis de la carga externa de competición en un periodo de congestión en hockey hierba. RICYDE Rev Int de Ciencias del Deporte. 2020; 16(60):143-52. https://doi.org/10.5232/ricyde2020.06003.

119. Russell M, Sparkes W, Northeast J, Kilduff LP. Responses to a 120 min reserve team soccer match: a case study focusing on the demands of extra time. J Sports Sci. 2015;33(20):2133-9.

120. Russell M, Sparkes W, Northeast J, Cook CJ, Love TD, Bracken RM, et al. Changes in acceleration and deceleration capacity throughout professional soccer match-play. J Strength Cond Res. 2016;30(10):2839-44. https://doi. org/10.1519/JSC.0000000000000805. 
121. Sangnier S, Cotte T, Brachet O, Coquart J, Tourny C. Planning training workload in football using small-sided games' density. J Strength Cond Res. 2019;33(10):2801-11

122. Silva P, Santos ED, Grishin M, Rocha JM. Validity of heart rate-based indices to measure training load and intensity in elite football players. J Strength Cond Res. 2018;32(8):2340-7. https://doi.org/10.1519/JSC.0000000000002057.

123. Smpokos E, Mourikis C, Linardakis M. Differences in motor activities of Greek professional football players who play most of the season (2016/17). J Phys Educ Sport. 2018;18:490-6.

124. Smpokos E, Mourikis C, Linardakis M. Seasonal changes of physical (motor) activities in professional Greek football players. Trends Sport Sci. 2018;25(2): 99-107.

125. Stevens TGA, De Ruiter CJ, Beek PJ, Savelsbergh GJP. Validity and reliability of 6-a-side small-sided game locomotor performance in assessing physical fitness in football players. J Sports Sci. 2016;34(6):527-34. https://doi.org/10.1 080/02640414.2015.1116709.

126. Stevens T, Twisk J, Savelsbergh G, Beek P. Quantification of in-season training load relative to match load in professional Dutch Eredivisie football players. Sci Med Football. 2017;1:117-25

127. Suarez-Arrones L, Núñez J. Sáez de Villareal E, Gálvez J, Suarez-Sanchez G, Munguía-Izquierdo D. Repeated-high-intensity-running activity and interna training load of elite rugby sevens players during international matches: a comparison between halves. Int J Sports Physiol Perform. 2016;11(4):495-9. https://doi.org/10.1123/ijspp.2014-0523.

128. Suarez-Arrones L, Pareja-Blanco F, De Villareal ES, Munguía-Izquierdo D, Portillo J, Sánchez-Medina L. Match-play activity profile in elite women's rugby union players. J Strength Cond Res. 2014;28(2):452-8.

129. Sullivan C, Bilsborough JC, Cianciosi M, Hocking J, Cordy J, Coutts AJ. Match score affects activity profile and skill performance in professional Australian Football players. J Sci Med Sport. 2014;17(3):326-31.

130. Sullivan C, Bilsborough JC, Cianciosi M, Hocking J, Cordy JT, Coutts AJ. Factors affecting match performance in professional Australian Football. Int J Sports Physiol Perform. 2014;9(3):561-6. https://doi.org/10.1123/ijspp.20130183.

131. Sweeting AJ, Aughey RJ, Cormack SJ, Morgan S. Discovering frequently recurring movement sequences in team-sport athlete spatiotemporal data. J Sports Sci. 2017;35(24):2439-45. https://doi.org/10.1080/02640414.2016.1273 536.

132. Tee JC, Coopoo Y, Lambert M. Pacing characteristics of whole and partgame players in professional rugby union. Eur J Sport Sci. 2019;20(39):1-12.

133. Tee JC, Lambert MI, Coopoo Y. GPS comparison of training activities and game demands of professional rugby union. Int J Sports Sci Coach. 2016; 11(2):200-11. https://doi.org/10.1177/1747954116637153.

134. Tee JC, Lambert MI, Coopoo Y. Impact of fatigue on positional movements during professional rugby union match play. Int J Sports Physiol Perform. 2017;12(4):554-61. https://doi.org/10.1123/ijspp.2015-0695.

135. Thornton HR, Delaney JA, Duthie GM, Dascombe BJ. Effects of preseason training on the sleep characteristics of professional rugby league players. Int J Sports Physiol Perform. 2018;13(2):176-82. https://doi.org/10.1123/ijspp.201 7-0119.

136. Varley MC, Aughey RJ. Acceleration profiles in elite Australian soccer. Int J Sports Med. 2013;34(1):34-9.

137. Varley MC, Gabbett T, Aughey RJ. Activity profiles of professional soccer rugby league and Australian football match play. J Sports Sci. 2014;32(20): 1858-66. https://doi.org/10.1080/02640414.2013.823227.

138. Vazquez-Guerrero J, Reche X, Cos F, Casamichana D, Sampaio J. Changes in external load when modifying rules of 5-on-5 scrimmage situations in elite basketball. J Strength Cond Res. 2018;34(11): 3217-24.

139. Vescovi JD, Frayne DH. Motion characteristics of division I college field hockey: Female Athletes in Motion (FAiM) study. Int J Sports Physiolo Perform. 2015;10(4):476-81. https://doi.org/10.1123/ijspp.2014-0324.

140. Vigh-Larsen JF, Dalgas U, Andersen TB. Position-specific acceleration and deceleration profiles in elite youth and senior soccer players. J Strength Cond Res. 2018;32(4):1114-22. https://doi.org/10.1519/JSC.0000000000001918.

141. Wehbe GM, Hartwig TB, Duncan CS. Movement analysis of Australian national league soccer players using global positioning system technology. J Strength Cond Res. 2014;28(3):834-42. https://doi.org/10.1519/JSC.0b013 e3182a35dd1.

142. Wellman AD, Coad SC, Flynn PJ, Climstein M, McLellan CP. Movement demands and perceived wellness associated with preseason training camp in NCAA division I college football players. J Strength Cond Res. 2017;31(10): 2704-18. https://doi.org/10.1519/JSC.0000000000002106

143. Wellman AD, Coad SC, Flynn PJ, Siam TK, McLellan CP. Perceived wellness associated with practice and competition in national collegiate athletic association division I football players. J Strength Cond Res. 2019;33(1):11224. https://doi.org/10.1519/JSC.0000000000002169.

144. White AD, MacFarlane N. Time-on-pitch or full-game GPS analysis procedures for elite field hockey? Int J Sports Physiol Perform. 2013;8(5): 549-55. https://doi.org/10.1123/ijspp.8.5.549.

145. White AD, MacFarlane NG. Analysis of international competition and training in men's field hockey by global positioning system and inertial sensor technology. J Strength Cond Res. 2015;29(1):137-43. https://doi.org/1 0.1519/JSC.0000000000000600.

146. White AD, MacFarlane NG. Contextual effects on activity profiles of domestic field hockey during competition and training. Hum Mov Sci. 2015; 40:422-31. https://doi.org/10.1016/j.humov.2015.01.007.

147. Yamamoto H, Takemura M, Iguchi J, Tachibana M, Tsujita J, Hojo T. In-match physical demands on elite Japanese rugby union players using a global positioning system. BMJ Open Sport Exerc Med. 2020;6(1):e000659. https:// doi.org/10.1136/bmjsem-2019-000659.

148. Young D, Malone S, Collins K, Mourot L, Beato M, Coratella G. Metabolic power in hurling with respect to position and halves of match-play. PloS one. 2019;14(12):e0225947. https://doi.org/10.1371/journal.pone.0225947.

149. Buchheit M, Al Haddad H, Simpson BM, Palazzi D, Bourdon PC, Di Salvo V, et al. Monitoring accelerations with GPS in football: time to slow down? Int J Sports Physiol Perform. 2014;9(3):442-5. https://doi.org/10.1123/ijspp.20130187.

150. Buchheit M, Allen A, Poon TK, Modonutti M, Gregson W, Di Salvo V. Integrating different tracking systems in football: multiple camera semi-automatic system, local position measurement and GPS technologies. J Sports Sci. 2014;32(20): 1844-57. https://doi.org/10.1080/02640414.2014.942687.

151. Jennings D, Cormack S, Coutts AJ, Boyd LJ, Aughey RJ. Variability of GPS units for measuring distance in team sport movements. Int J Sports Physiol Perform. 2010:5(4):565-9.

152. Edgecomb SJ, Norton Kl. Comparison of global positioning and computerbased tracking systems for measuring player movement distance during Australian Football. J Sci Med Sport. 2006;9(1):25-32.

153. Hodder RW, Ball KA, Serpiello FR. Criterion validity of Catapult ClearSky T6 local positioning system for measuring inter-unit distance. Sensors. 2020;20:3693.

154. Luteberget LS, Spencer M, Gilgien M. Validity of the Catapult ClearSky T6 local positioning system for team sports specific drills, in indoor conditions. Front Physiol. 20189.

155. Ogris G, Leser R, Horsak B, Kornfeind P, Heller M, Baca A. Accuracy of the LPM tracking system considering dynamic position changes. J Sports Sci. 2012;30(14):1503-11. https://doi.org/10.1080/02640414.2012.712712.

156. Frencken WGP, Lemmink KAPM, Delleman NJ. Soccer-specific accuracy and validity of the local position measurement (LPM) system. J Sci Med Sport. 2010;13(6):641-5.

157. TG AS, de Ruiter CJ, van Niel C, van de Rhee R, Beek PJ, GJ PS. Measuring acceleration and deceleration in soccer-specific movements using a local position measurement (LPM) system. Int J Sports Physiol Perform. 2014;9(3): 446-56. https://doi.org/10.1123/ijspp.2013-0340.

158. Sathyan T, Shuttleworth R, Hedley M, Davids K. Validity and reliability of a radio positioning system for tracking athletes in indoor and outdoor team sports. Behav Res Methods. 2012:44(4):1108-14. https:/doi.org/10.3758/s13428-012-0192-2.

159. Serpiello FR, Hopkins WG, Barnes S, Tavrou J, Duthie GM, Aughey RJ, et al. Validity of an ultra-wideband local positioning system to measure locomotion in indoor sports. J Sports Sci. 2018;36(15):1727-33. https://doi. org/10.1080/02640414.2017.1411867.

160. Alarifi A, Al-Salman A, Alsaleh M, Alnafessah A, Al-Hadhrami S, Al-Ammar MA, et al. Ultra wideband indoor positioning technologies: analysis and recent advances. Sensors. 2016:16(5):707.

161. Bastida-Castillo A, Gómez-Carmona CD, EDI C-S, Reche-Royo X, Ibáñez SJ, Ortega JP. Accuracy and inter-unit reliability of ultra-wide-band tracking system in indoor exercise. Appl Sci. 2019;9(5):939.

162. Douglas GA, Patrick R. Statistics notes: the cost of dichotomising continuous variables. BMJ. 2006;332(7549):1080

163. Delaney JA, Wileman TM, Perry NJ, Thornton HR, Moresi MP, Duthie GM The validity of a global navigation satellite system for quantifying small-area team-sport movements. J Strength Cond Res. 2019;33(6):1463-6. 
164. Hsu DY. Relations between dilutions of precision and volume of the tetrahedron formed by four satellites; 1994. p. 669-76.

165. Williams M, Morgan S. Horizontal positioning error derived from stationary GPS units: a function of time and proximity to building infrastructure. Int $J$ Perform Anal Sport. 2009;9(2):12.

166. Winter DA. Biomechanics and motor control of human movement. 4th ed. ed. Hoboken: Wiley; 2009.

167. Winter DA, Sidwall HG, Hobson DA. Measurement and reduction of noise in kinematics of locomotion. J Biomech. 1974;7(2):157-9.

168. Rader CM, Gold B. Digital filter design techniques in the frequency domain. Proc IEEE. 1967;55(2):149-71.

169. Carling C, Bloomfield J, Nelsen L, Reilly T. The role of motion analysis in elite soccer: contemporary performance measurement techniques and work rate data. Sports Med. 2008;38(10):839-62. https://doi.org/10.2165/00007256-2 00838100-00004.

170. Wundersitz DWT, Gastin PB, Robertson S, Davey PC, Netto KJ. Validation of a trunk-mounted accelerometer to measure peak impacts during team sport movements. Int J Sports Med. 2015;36(9):742-6.

\section{Publisher's Note}

Springer Nature remains neutral with regard to jurisdictional claims in published maps and institutional affiliations.

\section{Submit your manuscript to a SpringerOpen ${ }^{\circ}$ journal and benefit from:}

- Convenient online submission

- Rigorous peer review

- Open access: articles freely available online

High visibility within the field

- Retaining the copyright to your article

Submit your next manuscript at $\boldsymbol{\nabla}$ springeropen.com 